Charlie Gullström, Ph.D., Architect SAR/MSA

Visiting Associate Professor in Architecture, media, interaction and communication

Department of Architecture

KTH Royal Institute of Technology

10044 Stockholm, Sweden

e-mail: charlieg@kth.se Tel.0046-8-7909211,0046-707153425

\title{
Design Frictions
}

\author{
Author's version. Received by Springer: 25 May 2010 / Accepted: 17 June 2011 \\ Published by Springer London AI \& Society Vol 26/2011 \\ DOI 10.1007/s00146-011-0361-3 \\ ISSN 0951-5666 (Print) \\ 1435-5655 (Online)
}

\begin{abstract}
A fusion of architecture and media technology, video-mediated spaces facilitate collaborative practices across spatial extensions. This paper contributes an architectural perspective on presence design, exploring its potential to create architectural extensions that facilitate knowledge-sharing and remote presence. With the example of a mediated therapist, taken from the author's design-led research (Gullström 2010), the paper illustrates spatial design concepts (e.g. mediated gaze, spatial montage, shared mediated space), which, unaddressed, may be said to impose friction, and thus impact negatively on the experience of witnessed mediated presence (Nevejan 2007). Mediated presence cannot be ensured by design, however, by acknowledging that certain features are related to spatial design, a presence designer can monitor them and, in effect, seek to reduce the 'design friction' that otherwise may inhibit e.g. trust and knowledge-sharing. It concludes that a presence-in-person paradigm prevails in our society, founded on the expectations of trust and knowledge-sharing between individuals, and hereby addresses the contribution from presence design to architectural practice - as well as the reciprocal contribution from architecture to presence design - given that mediated spaces currently provide viable alternatives for meetings and interactions, hence with a fundamental impact on all human practices.
\end{abstract}

Keywords: presence design, architecture, mediated gaze, spatial montage, shared mediated space, trust, knowledge-sharing, design frictions.

\section{Introduction}

Whether a frescoed wall, a cave mural, a digital projection or an Italian Renaissance perspective, virtual spaces are representations of space that we encounter on a surface. Throughout history a broad range of practitioners -architects, artists, writers and filmmakers- have contributed hybrid design 
artefacts from a juxtaposition of real space and virtual space: mediated spaces. ${ }^{1}$ We may find ourselves immersed, by looking onto a surface in order to explore a three-dimensional reality, a vast panorama, a furious battle, a busy workplace or the fictional space of a book. Arguably, these are architectural extensions. As we encounter a virtual space, we always find ourselves inside a real space, which is the space we share with other people and things (Summers 2003: 43). ${ }^{2}$

Turning, then, to the designers of such hybrid spatial montage, we may observe how different features are combined - such as the mediated gaze in virtual pictorial space - to draw the observer into its spatial extension. ${ }^{3}$ Renaissance artists frequently used architectural orders: columns and pilasters as "signposts to mark the transition from actual to virtual space" (Steinberg 2001:155) - all in accordance with the Albertian concept of art as a 'window onto the world' ${ }^{4}$ Any art history book will describe Leonardo da Vinci's Last Supper as an exemplar, but my study on the origins of presence design shows that in addition to being an architect, engineer and artist, da Vinci was effectively a presence designer (Gullström 2010). Through its numerous reproductions, contemporary observers are acquainted with the Last Supper as a painting, rather than a spatial extension. (Fig. 1) However, by observing the Last Supper as part of the spatial context in which it was conceived, its function as part of a design scheme may be understood. (Fig. 2) The fact that the painting is a part of the design of a refectory provides the most important clue; it suggests that it is not just any painting or vista, not just any window onto the world. ${ }^{5}$

\footnotetext{
${ }^{1}$ This paper draws upon research presented in my doctoral thesis, where I apply the concepts of virtual and mediated space to architecture, proposing an extended architectural practice (Gullström 2010). I discuss architectural extensions that facilitate collaborative practices and explore the boundaries of architecture as a discipline by observing its assimilation of other media practices. As an extended practice also calls for an extended discourse, a preliminary conceptual toolbox is proposed, consisting of design concepts, some of which are presented in this article. The concepts are adapted from related visual practices and tested on design prototypes, which arise from my design-led research and experience in designing work and learning spaces.

${ }^{2}$ Following this simple distinction between of 'virtual' and 'real' spaces, David Summers divides 'real space' into social space, for which architects are the principal designers and personal space, for which sculptors are responsible - while virtual space is the mastery of painting and the graphic arts (Summers 2003: 43). While it is easy to disagree with Summers' division of labour and to characterize his definition as simplistic, its benefit is to make a spectator part of the activity on the scene: the spectator becomes an active user of mediated spaces.

${ }^{3}$ Velazquez' painting Las Meninas from 1656 (Museo del Prado, Madrid) is a good example, famously deconstructed by Michel Foucault in his opening of The Order of Things (Foucault 1966).

${ }^{4}$ This concept is first described in Leon Battista Alberti's treatise on painting De Pictura which appeared in Latin ca. 143536 (Alberti ca. 1435-36, 1970).

${ }^{5}$ Why would da Vinci choose a malfunctioning construction of perspective? This question has engaged art historians in a long-standing debate stretching over centuries and is referred elsewhere (Gullström 2010:67ff; Steinberg 1973, 1995, 2001; Ladwein 2007). In 1979, a Norwegian art critic showed that the mural was part of the spatial design of the refectory by providing an account of the full aesthetic context in which The Last Supper was commissioned and conceived, hereby criticizing his fellow art historians, who seemed to think that the mural's form and content were mere coincidence "... as if da Vinci's hands were free when it came to executing the motif" (Danbolt 1979: 70). Danbolt explained the techniques da Vinci used to assemble two different functions in response to the commission; he was a skilled artist, and it was obviously not due to a lack in skill that he opted not to follow the standard rules of perspective. We may safely conclude it was intentional.
} 

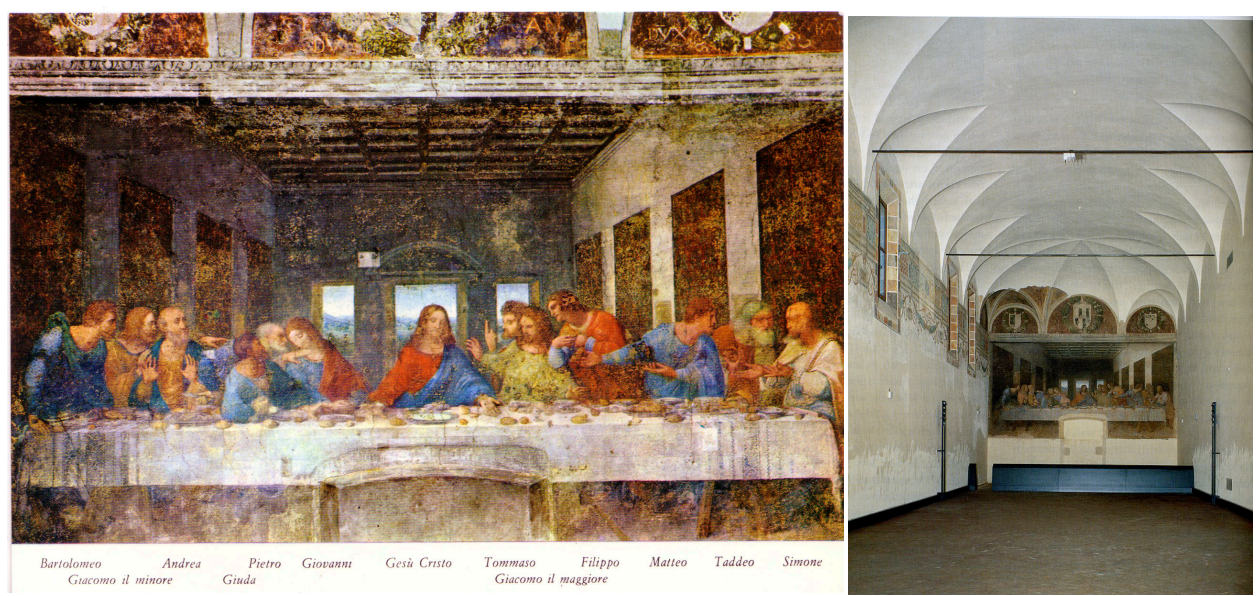

Fig. 1 The Last Supper by Leonardo da Vinci, depicting Jesus surrounded by his disciples. It has been debated whether the moment depicted in the painting is the institution of the sacrament - or the revelation of Judas' betrayal. (Postcard, Ed. $L$ Scrocchi, Milano)

Fig. 2 One encounters The Last Supper inside a large and currently empty room of the cloister Santa Maria delle Grazie in Milan. A visitor will note that the perspective does not seem to work and that the painting is placed at a surprising height. Why does the mural not conform to the rules of central perspective, which were well established at this time? In order to unfold the mystery of The Last Supper, its original design context must be observed: this is the refectory in which, day after day, the monks sat down to eat under the watchful gaze of Jesus and his disciples; in effect a shared mediated space.

I use this example to show, on a general level, that already then people were quite familiar with moving between different kinds of (virtual) space and, more specifically, that the refectory (including its artwork) is the result of a designer's intent to combine virtual space(s) and real space(s) in intricate ways. The monks are, symbolically, sharing the room - even dining - with Jesus who, however, is not physically present. In today's context it may be referred to as a 'virtual pictorial space', and as a form of communication made possible by means of art and architectural media. The monks are inside a real space when they encounter this virtual space. They are, thus, in a 'hybrid space', 'mixed-reality space', 'composite space' or, as I refer to it, the monks are in a shared mediated space.

What is new, today, is that it has become possible to populate these architectural extensions; to inhabit them in ways that allow people to interact and collaborate closely; to see and hear each other, in other words: to be present before one another whilst remaining in different locations. Designing for presence therefore implies the design of shared mediated spaces that enable people to collaborate as well as they might, for example, in their conventional workplace, possibly designed by architects. In enabling audiovisual extensions in real time, presence design emerges as a new field, exposing architectural discourse and practice to radical new concerns.

Architectural design is conventionally executed by 'brick and mortar', but new building materials are developing everyday, some adapted from the field of media and communications. Delimiting the discussion to my own design practice, which has explored video as a 'building material' and design component over ten years, this paper focuses the design issues that enable people to meet, collaborate and interact in shared mediated spaces in real time: presence design as architectural design.

In relating the needs for presence to spatial and temporal design, it is necessary to discern between different functionalities and expectations of meetings and interactions. We may ask whether it is 
primarily by convention that we commute to work, or whether human co-presence is an actual prerequisite for the professional work performed? While it can be argued that relationships may benefit from physical contact between humans (e.g. the need to momentarily touch someone's arm, or to shake hands) most work-related collaborations do not rely on physical contact as much as they rely on the potential exchange of knowledge, information transfer, direct access to expertise and flow of ideas between individuals. These are knowledge management processes in which the concept of trust is a qualifying factor. In effect, trust and presence are closely linked (Nevejan 2007, 2009).

The technological development that I refer to has a fundamental impact on the nature of human communication and interaction, across all practices. Thus it necessarily affects architectural design, its practitioners; and its academics. A proposed synthesis of architectural and technical design creates a significantly expanded potential for knowledge sharing, with potential to reformulate the practice and theory of architecture itself.

My research concludes that a presence-in-person paradigm prevails in our society, founded on the expectations of trust and knowledge-sharing between individuals. Sustaining this paradigm, in particular within work and learning contexts, a design convention has developed in which meetings and interactions are achieved by means of gathering people in one geographic location at the same time. Given that mediated spaces, specifically synchronous audiovisual spatial extensions using video and media technology as design components, may provide viable alternatives for meetings and interactions, the implications for workplace design are noteworthy. My study thus explores the contribution from presence design to architectural practice - as well as the reciprocal contribution from architecture to presence design.

I will briefly explore the foundations of a presence-in-person paradigm, arguing that, in line with the emerging network society, it is currently renegotiated with implications for architectural practice and theory. My focus is the relationship between presence design and architecture, with a particular interest in the implications for work and learning contexts where dialogic interaction and close collaboration is crucial. This design-led research is based on my reflective practice first, as architectural designer (1990-2005) specialised in workplace design, and secondly as presence designer (2000-2010). It thus summarizes work carried out over a long period of time during which an iterative research-by-design process has developed from combining my experiences from practice with the theoretical and analytical tools of a reflective practitioner (Schön 1983).

To address knowledge management as a spatial and temporal design issue assumes a correlation between spatial organization and human interaction, which is a long-standing debate, not least within architectural theory. There is, for example, no scientific evidence that an open plan office layout stimulates more interaction than a cell-office layout (Steen 2009) but space syntax theory has, to an extent, shown that spatial features such as proximity, visibility and layout stimulate interaction and collaboration (Hillier 1996, Allen 1977, Nonaka \& Konno 1998, Sailer 2010). 
My study is equally informed by research that has determined factors that may contribute to poorer synchronizing (Argyle \& Cook 1976); and 'frictions' (Davenport \& Prusak 1998) that inhibit knowledge-sharing in human interaction and collaborative co-present contexts. These are, for example, mutual gaze and trust. In effect, to be able to achieve mutual gaze has been observed as a key element in establishing trust, also in mediated interaction (Heath \& Luff 1992, Heath et al 1995, Rocco 1998, Acker \& Levitt 1987, Ishii \& Kobayashi 1992, Fullwood 2006). As noted by Caroline Nevejan (2007) trust is a prerequisite to the individual experience of presence in mediated environments, contributing a 'sense of being there' or of 'non-mediation' (IJsellsteijn \& Riva 2003; Lombard \& Ditton 1997; Held \& Durlach 1992).

Trust is, further, a core element in the body of 'informal and tacit practices' which sustain knowledge-sharing in accordance with Polanyi's notion of tacit knowing (Polanyi 1958, 1966) and Wittgenstein's concepts of rule-following and collectively established meaning (Wittgenstein 1953). A large body of existing research from the area of dialogue, skill and tacit knowledge (e.g. Göranzon et al 2006) may thus be applied to presence design.

In the following, I will attempt to show how the issue of trust relates to architectural design - if by architectural design, we also encompass the spatial extensions enabled through presence design.

\section{Presence design research}

A large body of research that informs the design of mediated spaces thus concerns the concept of presence. In effect, an often-referred-to definition of (tele-)presence includes a reference to architectural design: "the use of technology to establish a sense of shared presence or shared space among geographically separated members of a group." (Buxton 1992) ${ }^{6}$ To date, however, an architectural design perspective has been lacking in presence research. My research shows that presence research is characterised by sharp disciplinary boundaries and identifies a conceptual gap: presence research typically fails to integrate aesthetic concepts that can be drawn from architecture and related visual practices.

It is a currently diversified field, spanning media space research, cognitive science, (tele-)presence research, interaction design, ubiquitous computing, second-order cybernetics, and computer-supported collaborative work. ${ }^{7}$ With the proposal that its discourse is characterized by the separations of disciplinary boundaries, and that architecture, design and artistic practices are insufficiently represented, I argue for a transdisciplinary design-led approach, where presence research meets

\footnotetext{
${ }^{6}$ It can be argued that architecture by definition involves a 'use of technology'. Hence the definition would benefit from delimitation, such as 'the use of communication technology'.

${ }^{7}$ Presence research is a recently established field and primarily formulated from the perspectives of cognitive science and communication technology. Lombard \& Ditton's seminal article from 1997, "At the Heart of it All: The Concept of Presence", provides an important conceptual framework by summarising the contribution from researchers from cognitive science, neurology, virtual reality and computer graphics (Lombard \& Ditton 1997).
} 
architectural design and incorporates tools and strategies derived from related visual practices. This is the background to my own contribution and proposal that presence design is distinguished as a separate field (Gullström 2010). ${ }^{8}$

It is a major concern within presence research to distinguish specific criteria for mediated presence. ${ }^{9}$ One of its main contributors, Wijnand IJsselsteijn, proposes a presence theory which acknowledges that a spatial relationship is established when mediated presence occurs. This presence theory "assumes that for presence to occur, we first must direct our attention to the media environment at hand. Second, the environment itself needs to have spatial extent, putting requirements on its immersive qualities in terms of necessary depth cues, field-of-view, etc. Third, the ongoing construction of our sense of place is based on a limited number of 'reality tests'. If what is 'out there' responds in a fast, consistent and reliable way to our real-time sensorimotor probing - transforming appropriately as we move our heads and bodies, changing predictably as we interact with elements of the immersive environment -this will establish a basis for our perception of being part of the environment." (IJsselsteijn 2004: 165) To explain why a mediated space which is "low on visual realism" also can enable an experience of presence, he points to the role of active perception on behalf of a user provided "our sense of place is continuously and reliably supported by robust, real-time sensorimotor correlations." (Ibid: 166).

What I draw from IJsselsteijn's research is that spatial design plays a significant role in the process in which presence and trust are established: what he refers to as 'reality tests' (Ibid: 165). As part of negotiating trust and presence, a user will attempt to establish the spatial relationship between the space in which s/he finds herself (i.e. a real space) and the remote spaces represented e.g. on a wall (virtual space). In summary, mediated presence involves the following functions:

(1) Attention on behalf of the remote participant who is about to experience mediated presence;

(2) The environment itself needs to have spatial extent and immersive qualities allowing a user to understand the remote location (depth cues, field of view);

(3) an ongoing construction of a sense of place has to be triggered;

(4) feedback from the remote environment should be swift, consistent and reliable in response to real time sensory motor probing. A concluding remark from another study similarly points toward the relationship between presence research and architectural design: "experiencing presence requires the reproduction of the physical features of external reality; the possibility of interaction and free action, and the creation and sharing of the cultural web that makes meaningful - and therefore visible - both people and objects populating the environment.” (IJsselstein \& Riva 2003)

\footnotetext{
${ }^{8}$ Nevejan (op.cit.) similarly provides a design perspective.

${ }^{9}$ I do not go in to detail about how to measure the experience of 'mediated presence'. To develop scientific measures has been a primary concern of the broad and interdisciplinary field of presence research, partly hosted by the International Society of Presence Research (ISPR). It is complex because it involves psychological processes and ISPR recognizes that "researchers face significant challenges in developing valid and reliable measures of presence" (www.ispr.info downloaded 090618). Two general approaches, subjective and objective measures, have informed the 'ISPR Measures Statement and Compendium', available at: http://www.temple.edu/ispr/frame_measure_t.htm.
} 
Hence, my own design-led research was not needed to further confirm that a sense of presence can be achieved in mediated spaces, but rather to address what the contribution from architectural design entails; and how the combination of spatial and technical design that supports remote presence and mediated dialogic interaction may be refined, by the integration and application to different contexts of work and learning.

As noted by researchers who have sought to define the prerequisites for (witnessed) mediated presence, the experience of mediated presence is individual and negotiated as part of a process to establish trust and confirmation from the remote party/parties (IJsselsteijn 2004; IJsselsteijn \& Riva 2003; Nevejan 2007). While my focus is on the spaces in which mediated interaction occurs - the mediated spaces of presence design - Caroline Nevejan has addressed presence design with a specific focus on the concept of trust (Nevejan 2007). Based on a distinction between natural presence and witnessed mediated presence, she relates the design of presence to the design of trust in social interaction. Arguing that there are social implications, which designers are little aware of, concerning the way trust and truth are negotiated between people, Nevejan stresses the need for swift feed-back mechanisms (to provide an expected 're-action' to an action) generally in designing for social interaction (ibid: 252). Her study shows that mediated presence may increase the moral distance between actors who collaborate, due to the limited sensorial exchange, thus with a potential negative effect on trust. Nevejan proposes a conceptual framework for the new configurations of time, space, action and relation that is enabled through presence design and no longer are dictated by "physical presence'. She refers to this as the YUTPA framework where YUTPA is an acronym for "being with You in Unity of Time, Place and Action" (Cf. Nevejan 2009). The word Unity here refers to a specific configuration between four dimensions that a certain product or process design imposes on the user, and which favours certain interactions while excluding others. ${ }^{10}$

My own design-led research has shown that mediated spaces can provide sufficient audiovisual information about the remote space(s) and other person(s), allowing the subtleties of nonverbal communication to inform the interaction. Based on my personal design experiences, I found that in designing for presence, certain spatial features have an effect on the user's ability to experience a mediated spatial extension (sense of a shared mediated space), which in turn, can facilitate the experience of mediated presence. My conclusion is that certain spatial tools play an important role in the process in which trust and truth is negotiated, hence with an impact on knowledge-sharing.

Our designer observations comply with the general requirements for (witnessed) mediated presence and it is my concern, here, to substantiate such observations, not by further claims that mediated spaces can work, but rather by showing how many of the concerns Nevejan and IJsselsteijn raise, precisely are spatial design considerations.

\footnotetext{
${ }^{10}$ She writes that the specific configurations enable human beings to "enact their being, witness each other, tune and perform their presences." (Nevejan 2009)
} 
A comment on my intertwined role as designer and researcher is in place. As designers, my colleagues and I have explored the potential of presence design over several years, by refining 'what works' and by developing our design prototypes, from applying them to new contexts, following the generic prototyping methodologies that characterize design practices. ${ }^{11}$ One could say that in each new project, we 'tick off' criteria such as those proposed by IJsselsteijn (2004: 165), to check that it still 'works' However, our focus is on refining the combination of spatial and technical design that facilitates mediated interaction. Therefore, several of the design concepts I discuss here are based on a solution that enabled mutual gaze in mediated interaction, which already 'worked' ten years ago, but which we improved over the years.

As a researcher, in turn, I reflect upon the different design experiences and use them as examples in an explorative study concerning the wider implications of presence design in relation to architectural design. With the a priori knowledge that mediated spaces can serve knowledge-sharing, I theoretically explore its potential for practices where trust is an essential factor. This is for example the case in collaborative work and learning practices, where practical knowledge is at the core. Thus, by establishing that mediated workplaces can support knowledge-sharing effectively, I propose an extension of the discourse in workplace design. I discuss how presence design can contribute viable solutions to knowledge management. Central here is the concept of shared mediated space, established as part of the experience of remote presence and founded in the exchange of audiovisual information.

Witnessed mediated presence cannot be ensured by design. However by acknowledging that certain features are related to spatial design, the presence designer can monitor them and, in effect, seek to reduce the 'friction' that otherwise may inhibit the experience of mediated presence. This notion of 'friction' relating to spatial design will be introduced below, as part of a discussion on the potential for knowledge-sharing and remote presence in collaborative work practices. My expanded use of the term -design friction - is an attempt to identify concepts related to spatial design which, unaddressed, may be said to impose friction and thus impact negatively on the experience of presence. The term design frictions thus summarizes my contribution to presence research: It consists of identifying such design concepts that may impact on the experience of mediated presence and thus benefit future practitioners and presence design research.

Of the spatial design frictions that I have identified, I will briefly illustrate a few - e.g. mutual gaze, spatial montage, shared mediated space, off-screen space - using two examples below. ${ }^{12}$ The first is designed by my colleague Aase Schibsted Knudsen, currently a presence designer in Norway. ${ }^{13}$

\footnotetext{
${ }^{11}$ As formulated by Herbert Simon (1969) as well as Donald Schön's concept of a reflective practitioner (1983)

${ }^{12}$ The above discussion and notion of design friction is further substantiated in my doctoral thesis where I apply the concepts to mediated workplaces I have designed for different user contexts. I provide a history and theory of presence design on the basis that similar aesthetic concepts have been used previously in related visual practices (Gullström 2010:149ff).

${ }^{13}$ The designers behind the event represent the Shared Virtuality research group of Lillehammer University College, led by Professor Schibsted Knudsen as part of the project Television in a Digital Environment (http://tide.hil.no/; cf. Knudsen \&
} 


\section{The example of Atwood in Lillehammer 2008}

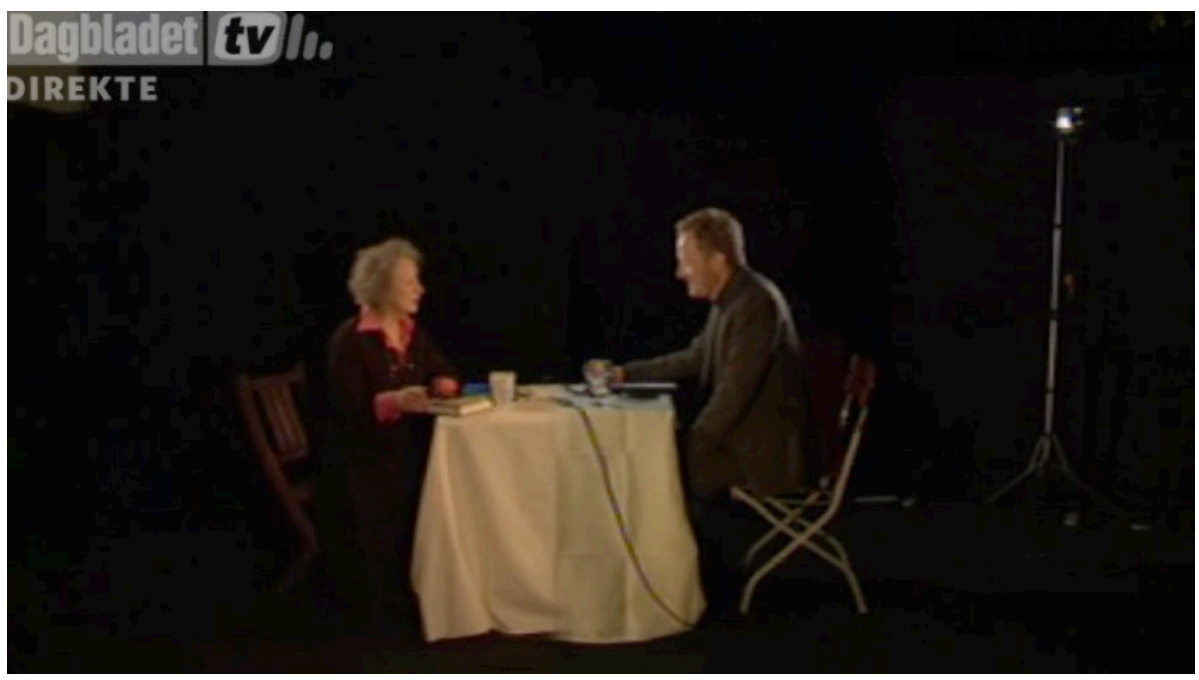

Fig. 3 Renowned writer Margaret Atwood shares a table with Simen Ekern, op-ed editor of the Norwegian Newspaper 'Dagbladet'. Image captured from live streaming (Dagbladet 2008). For details see Knudsen \& Puijk 2009.

'What a thrill it is to be here!' Margaret Atwood exclaimed as she addressed the audience of the Norwegian Festival of Literature in May 2008. Atwood was invited to discuss her recent book Oryx and Crake, from 2003, with Simen Ekern, op-ed editor of the Norwegian newspaper Dagbladet, and to perform a public reading. (Fig. 3) The open-air venue at Lillehammer was brimming with excitement as Atwood and Ekern sat down for an informal chat, facing one another across the small dining-room table, which had been dressed with a white tablecloth, on the elevated stage. The high expectations were of course due to the fact that Margaret Atwood is a renowned writer, but also to her being present in Lillehammer whilst actually remaining in Toronto, Canada. The Lillehammer performance venue was, in fact, temporarily extended to Toronto and to those witnessing her reading, it was clear that Margaret Atwood both was, and was not, present in Lillehammer. ${ }^{14}$

Puijk 2009). LongPen Signature Solutions ${ }^{\mathrm{TM}}$, also contributing to the event, declare that 1.2 tonnes of carbon emissions were saved (http://www.longpen.com)

${ }^{14}$ The Lillehammer project has implemented a teleprompter-based design concept to achieve mutual gaze, developed by myself and Mats Erixon 1999-2003, as part of interdisciplinary research to which also Schibsted Knudsen has contributed (for details, see Gullström 2010: 177ff). 


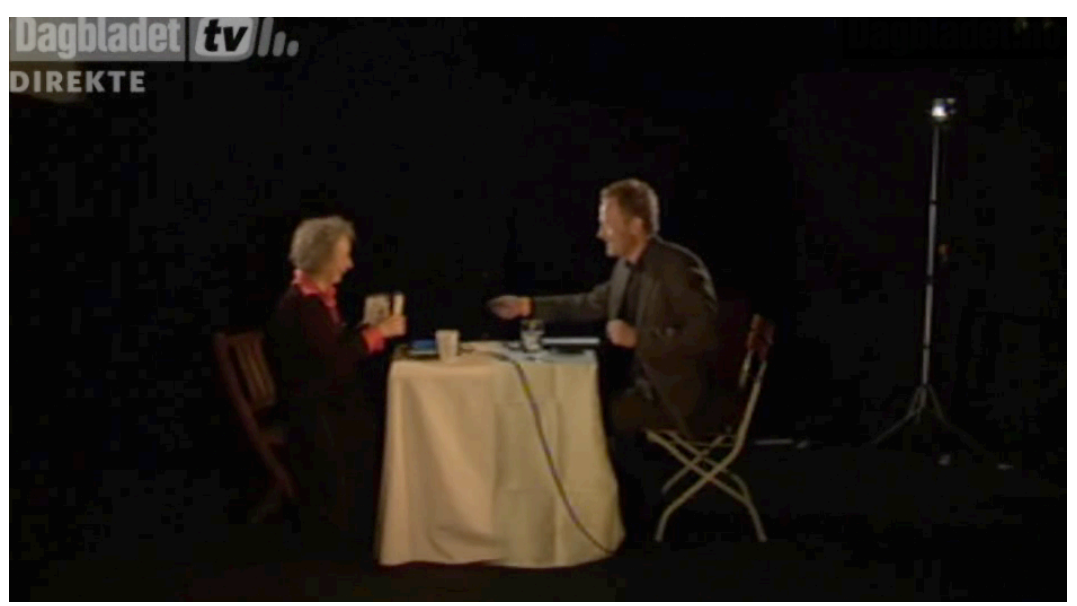

Fig. 4. Ekern seamlessly hands over the book that Atwood is here to sign.

At one point the host, Ekern, hands over Atwood's book in order for her to initiate the reading, as seen above. (Fig. 4) Although some may have interpreted this as pure magic, the explanation had already been laid out before the audience..$^{15}$ This presence design enabled Atwood and Ekern to achieve eye contact, creating an absorbing atmosphere, whereby the audience was drawn into the intimate exchange onstage. It is only when the dialogue ends, and Ekern leaves the table, that we experience an odd situation. (Fig. 5) Margaret Atwood is suddenly left alone and by herself at the table, while we become aware that she is not actually here with us. As spectators, we are at once thrown back into a more conventional role of the passive audience; while in the moment previous, we were actively engaged in a dialogue on a live stage.

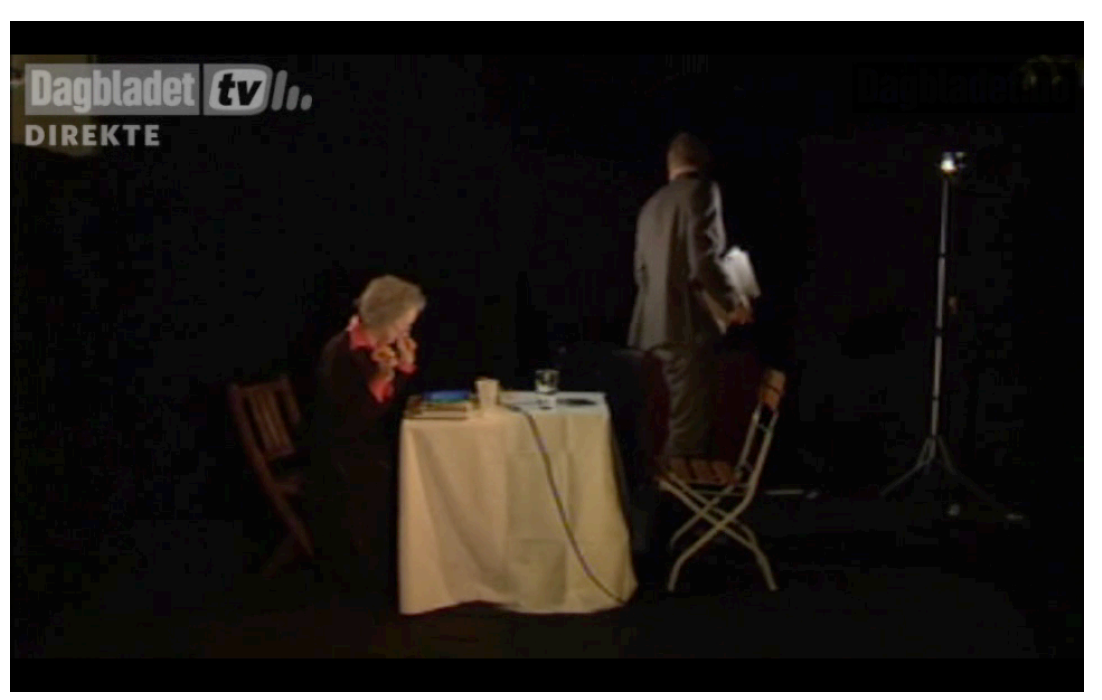

Fig. 5. Ekern leaves the stage and Atwood is left alone.

\footnotetext{
${ }^{15}$ To provide an illusion of gazing straight at an anchor or TV audience, a remote participant in a conventional live set-up will need to look into a camera lens. Whereas it would be more natural (thus preferred) to look at the TV anchor one addresses, the display of the latter and the camera are usually not aligned (usually because a large camera would block such a display). As an alternative, a teleprompter-like design, which involves reflective mirrors, may be used. This enables an interviewee to look straight at the journalist $\mathrm{s} / \mathrm{he}$ is addressing whilst still being captured by a camera lens.
} 


\section{Spatial montage}

In observing the underlying design strategies which have enabled this and other seamless extensions of space, I will distinguish between attempts to create architectural extensions and designs which aim toward spatial relocation, arguing that in juxtaposing material and immaterial elements, designers today face similar challenges and opportunities to those Sergei Eisenstein addressed through his concept of spatial montage in 1938. Eisenstein regarded architecture as the predecessor to film and he often compared the three-dimensional capacity of the new media with that of architecture: "The Greeks have left us the most perfect examples of shot design, change of shot, and shot length." (Eisenstein ca 1938: 112).

In this day and age it can perhaps be argued that architecture, through the integration of new media, can recuperate its capacity for 'tertium quid'; Eisenstein's reference to the third element, or entity, which constitutes a whole greater than the sum of its individual shares (Eisenstein 1992). Recent developments in art, media and architecture in fact point towards a fruitful interweaving of practices. This has potential also for presence design as a new practice transgressing disciplinary boundaries. Collaboration between several professional skills, however, requires a shared foundation and widespread understanding of the spatial and technical considerations which are involved in presence design. The Atwood example serves to contribute an awareness of how spatial mechanisms operate, specifically the relationship between different spatial layers, and its impact on human patterns of behaviour. As in real spaces, activities in mediated spaces are affected by a spatial order, and it is necessary to explore the underlying power structures of the new hybrid spatialities which humans increasingly occupy. The example exposes a range of design strategies available to presence designers today. While a TV audience is used to live broadcasts to which a participant contributes from a remote location, it is unique that a journalist and his interviewee are seen to share the stage and convincingly look each other in the eyes. That participants can achieve mutual gaze is widely accepted as a key element in presence design, based on the knowledge that subtleties of nonverbal communication are easily lost (Heath \& Luff 1991, Rutter et al 1984), however it is not always understood as a design element.

Let us observe the venue in some detail. (Fig. 6-8) The design which clearly proved to include Atwoods remote location, to the Lillehammer space, can be described in terms of spatial montage: the two spaces are juxtaposed, in such a way as to create a mediated space. A large display facing the audience features Atwood and Ekern opposite one another, sharing a table. On the right hand side of the stage, however, we find Ekern sitting by himself, in profile. One section of his table is visible. Ekern is actually facing a teleprompter-based design piece, which allows him to look Margaret Atwood straight in the eyes. The web-streaming footage only occasionally allows us to see exactly what he sees, and has prioritized the edited view of the two in profile. Ekern is present in person, and in conjunction with effective light design and acoustic synchronization of the two spaces (Atwood, in fact, remains indoors, which is hardly noticeable), this design contributes to our experience, as 
spectators, of observing a shared a venue. This design which clearly extended Atwood's remote location to the Lillehammer space can also be described as an example of spatial montage: the two spaces are juxtaposed to effectively create a mediated space.

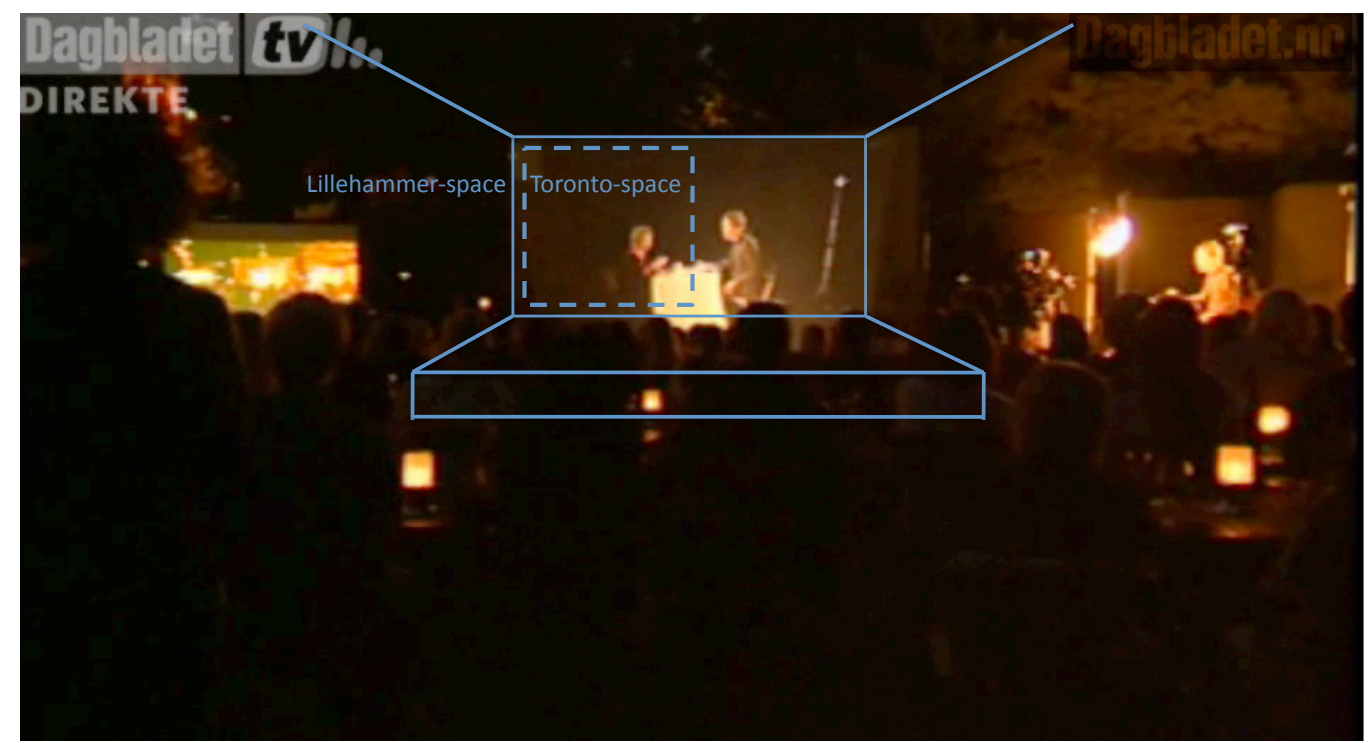

Fig. 6 The concept of spatial montage: a smaller space (Toronto) is added to a larger space (Lillehammer). Together the two establish a mediated space. The fact that Atwood is seated in a studio in Toronto, yet appears on a live outdoor stage is well concealed.

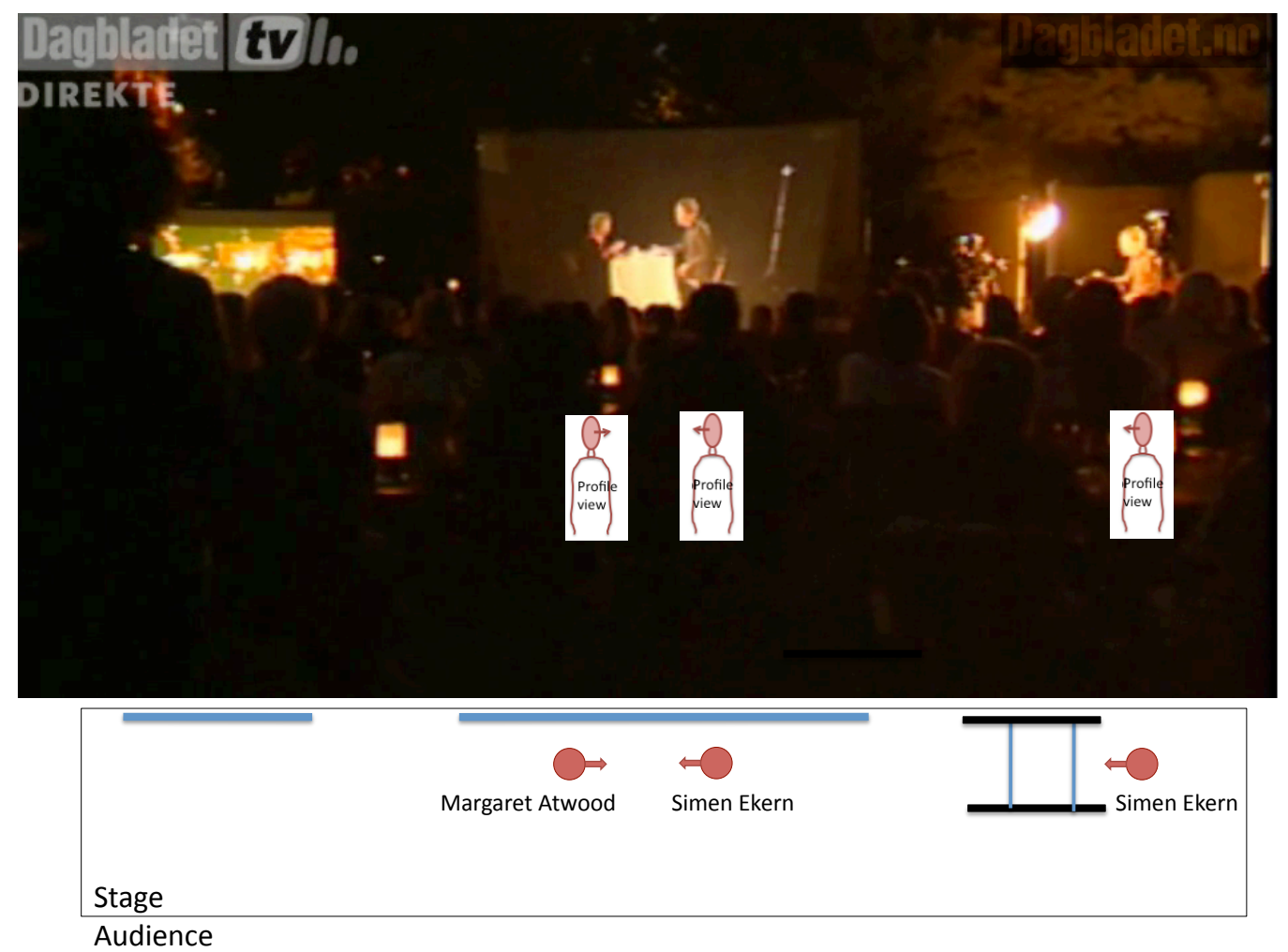

Fig. 7 Schematic analysis of the spatial layout as perceived by the audience. The red arrow on the plan denotes the direction of gaze of the persons seen on stage. As noted, Simen Ekern appears twice. To the right, Ekern is seen in profile, facing Atwood who appears in the teleprompter-based design prototype before him. The teleprompter design in my plan is represented as a volume in black. 

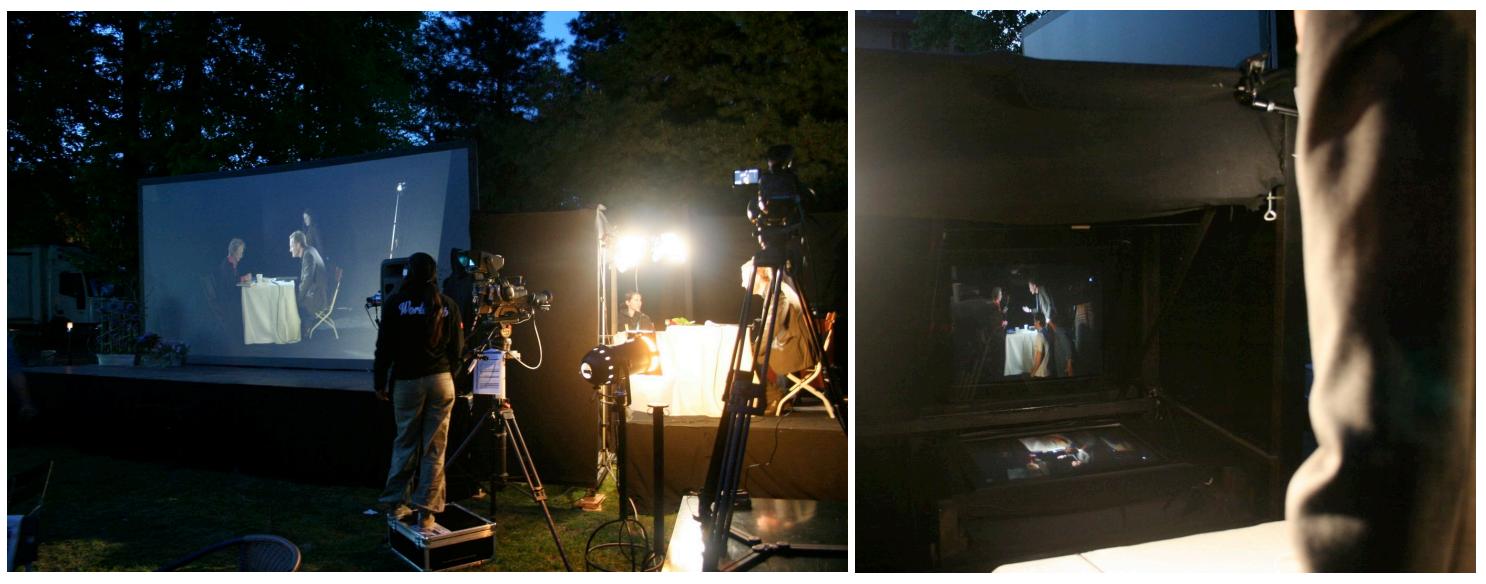

Fig. 8 The teleprompter-based design as seen from the audience (left) and from Ekern's perspective (right). Photos by Gro Vasbotten.

Ekern effectively appears twice onstage, a fact that may be referred to as a spatial confusion. We see him to the right, seated at a table by the teleprompter design; and also centre stage, sharing a table with Atwood. In design, there are always many different ways to achieve a similar set-up. One possibility here could be to move Ekern and the teleprompter design to centre stage, and place Atwood's display in such a way that it shields Ekern's table. As illustrated below, such an alternative would allow Ekern to appear only once, and in person, on stage. As in the original set-up, it would also allow both parties to turn to address the audience on occasion. (Fig. 9)

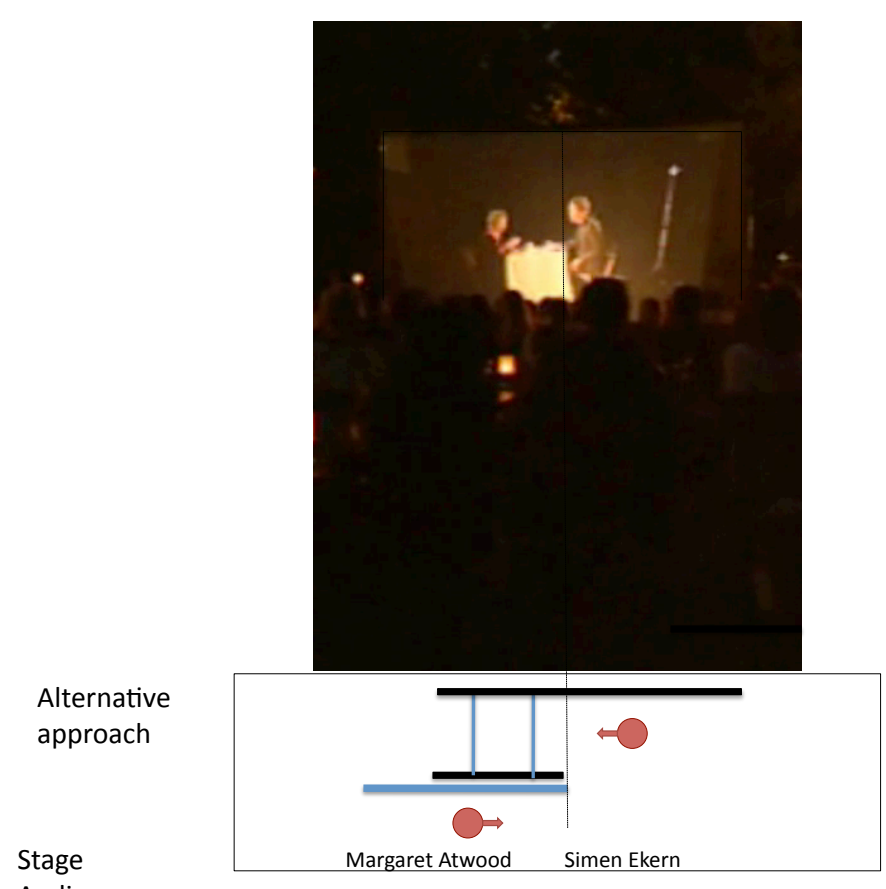

Audience

Fig. 9 The 


\section{The example of a mediated therapist}

In the spring of 2008, a mediated therapist treated twenty patients remotely, in a workplace designed to support mediated presence. ${ }^{16}$ What is particular about this example is that it concerns a specific form of dialogic interaction, where trust is a core element.

On the day of the first appointment, a patient was received in person, inside a mediated consulting room, seen below. (Fig. 10) The patient subsequently met the doctor six times in the same space. On entering the room on these later occasions, the patient faced the doctor, visibly seated at her desk, but nevertheless in a different pace. The desk was part of a furniture series designed to enable mutual gaze and mediated presence (Gullström 2010 :133ff). The interiors of the two spaces were similarly furnished.

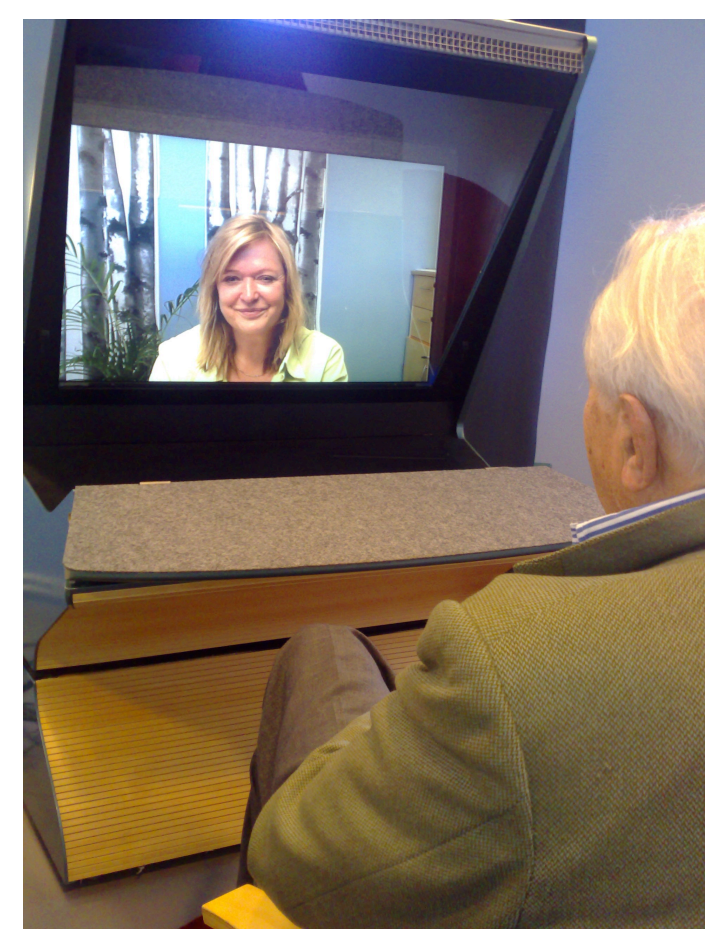

Fig. 10 The mediated consulting room with the piece of furniture designed to enable mutual gaze by incorporating reflective mirrors. To the right, a sitting area where the initial doctor-patient encounter took place. Both therapist and patients expressed positive feelings in regards the interior design which was deemed suitable for the intimacy required.

The length of each therapy session was approximately one hour, during which the therapist assessed the patient's health using conventional tools from Cognitive Behavioural Therapy (CBT), based on many years' experience in treating similar patients. ${ }^{17}$ The therapist took special notice of how she greeted patients remotely but followed the same procedures as if she had treated patients in a real

\footnotetext{
${ }^{16}$ User study I conducted in 2008 within the 'Mediated Spaces' research group of the VINNOVA Centre of Excellence for Sustainable Communications, Royal Institute of Technology. Responsible for presence design: myself and Leif Handberg based on earlier prototyping by myself and Mats Erixon.

${ }^{17}$ The doctor who participated in the study, Agneta Ekman, MD, is a private consultant and specialist in psychiatry and occupational health. Patients were diagnosed using MINI (Mini International Neuropsychiatric Interview, rev. 060405), their mood was assessed using MADRS (the Montgomery-Åsberg Depression Rating Questionnaire), HAD (a diagnostic instrument Hospital Anxiety and Depression Scale) as well as EQ (diagnostic instrument by EuroQoL Group 1990).
} 
space. She was able to fully perform her professional assessment of patients during the mediated dialogic interaction.

I use this example because it shows that a mediated architectural extension serves this particular form of dialogic interaction sufficiently well for the doctor to perform her professional assessment. From the study, the mediated therapist concluded that she could carry out her work as well as she would have in a real space facing the patients. In effect, the doctor experienced the mediated therapy was less mentally exhausting than conventional practice, a result which is also supported by previous research (de las Cuevas et al 2006). The design explicitly provided a situation where the patient 'was seen' and where the design provided a framing in which the doctor's gaze became more prominent than in a shared real space. Further, the study showed that the patients' health improved as well and that they expressed a positive experience of remote presence and mediated therapy. ${ }^{18}$

\section{Spatial design concepts: Mutual gaze and shared mediated space}

Other studies in telemedicine and telepsychiatry similarly indicate positive results. ${ }^{19}$ What distinguishes this particular user study is the possibility to achieve mutual gaze. Interviews with patients who participated in the treatment confirmed a strong sense of presence, and several expressed they sometimes forgot the doctor was somewhere else. A combination of life-size projection, the possibility for mutual gaze, an overall integrated design and a welcoming environment contributed to this experience.$^{20}$ Furthermore, the design explicitly provided a situation where the patient 'was seen' and where, perhaps, the doctor's gaze was more prominent than in a shared real space. The therapist was aware that gazing is an important and noteworthy feature and experienced that the remote therapy sessions indirectly provided an opportunity for training patients with cognitive disorders. Failure to develop typical mutual gaze behaviour is one of the earliest signals of severe social and communicative disorders, or of autism (e.g. Senju \& Hasegawa 2005: 128).

The distinct framing provided by the design, which excluded other, perhaps less important objects and parts of the room (outside the camera view), contributed focus and proximity to the conversation. It defined a shared mediated space in which both parties were aware that interaction could take place.

\footnotetext{
${ }^{18}$ The most common diagnosis reported were major depression, dysthymic disorder and generalized anxiety disorder (GAD) Five had bipolar depression. A majority of patients was treated with antidepressants and/or mood stabilizers as part of CBT. After seven therapeutic sessions, patients' satisfaction and impression of the mediated therapy treatment were reported in a questionnaire, from which positive responses were concluded; I also conducted five interviews with Dr Ekman and five with patients; Ekman (2009) reported 85\% patient improvement measured in MADRS (0-11) and HAD (0-6), in accordance with previous studies regarding the effectiveness of telepsychiatry.

${ }^{19}$ For an overview of the extensive body of research in telemedicine, see e.g. Latifa 2008, Sinha 2000, de las Cuevas et al 2006; for telepsychiatry, see e.g. Gunter 2009, Norman 2006, O'Reilly et al 2007). The benefit of telemedicine in remote areas, where medical infrastructure is poor, frequently due to lack of resources and to the difficulty of attracting expertise to serve the area, is reported in Canada (Morazin 1997). Results demonstrate that patient response to telemedicine is overwhelmingly positive, above 90 percent (e.g., Dick et al. 1999). Keating \& Mirus (2003) report positive results from mediated spaces which enable deaf people to communicate using manual visual language, in many cases their native language, across space and time zones.

${ }^{20}$ It is very likely that the context of use was also a contributing factor: all patients were ill and very grateful for the possibility of faster treatment through participating in the study. Interviewees expressed they felt that the personal charisma of the therapist was a contributing factor. The 20 patients, ages spanning from 20 to 78 years, were referred to the study by general practitioners and psychiatrists in the Stockholm area.
} 
This observation is confirmed also from other design experiences, where remote participants expressed that gazing in mediated spaces is more intense than in real spaces. A likely explanation is that the designed mediated space makes both parties aware of the limitations of shared mediated space: if you look (or walk) outside this area, your adversary does not know what you see (or where you are).

The illustration below shows the layout of the mediated consulting-room and the therapist's office, respectively. (Fig. 11) This representation follows the convention from architectural design, where the placement of different furniture is indicated. One could also choose to represent what the camera captures in each location, as shown in Fig. 12-13. The shared mediated space which emerges as the two rooms are joined can also be referred to as a spatial montage and represented as such.

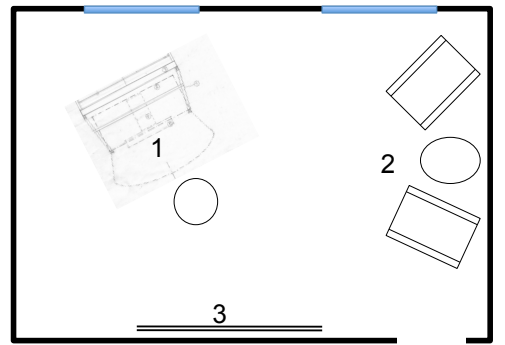

'CONSULTING-ROOM'

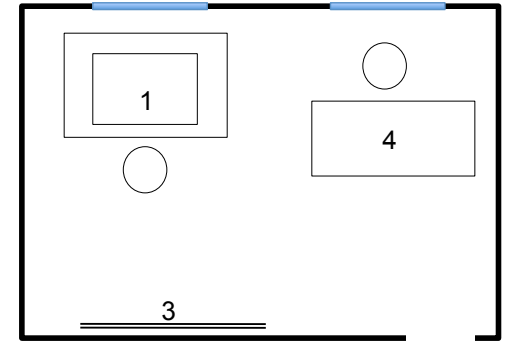

'THERAPIST'S OFFICE'

Fig. 11 The layout of the two rooms, each of which measured 3,2 $x$ 4,5 m. Key: (1) Desk and mediated extension; (2) Sitting area; (3) Back-drop (same in both locations).

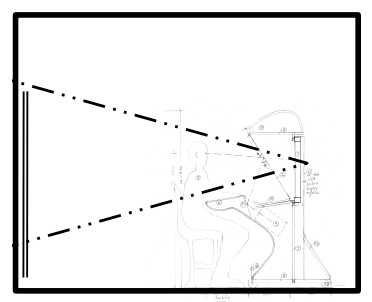

Fig. 12 The section illustrates what the camera captures of the room.

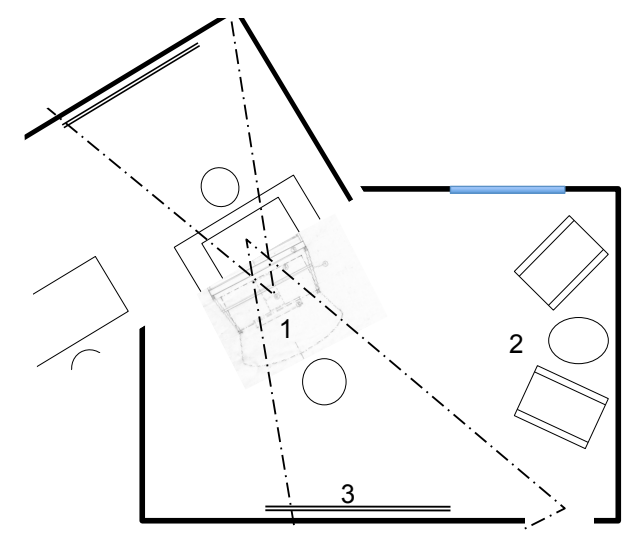

Fig. 13 The shared mediated space which emerges as two rooms are joined can also be represented as a spatial montage. 
To monitor gaze and mutual gaze can thus be regarded as spatial considerations which may determine the user's ability to interpret the remote space and therefore to trust the experience at hand. A teleprompter-based design can be achieved by simple means, as illustrated by the mediated glassdoor below. (Fig. 14)
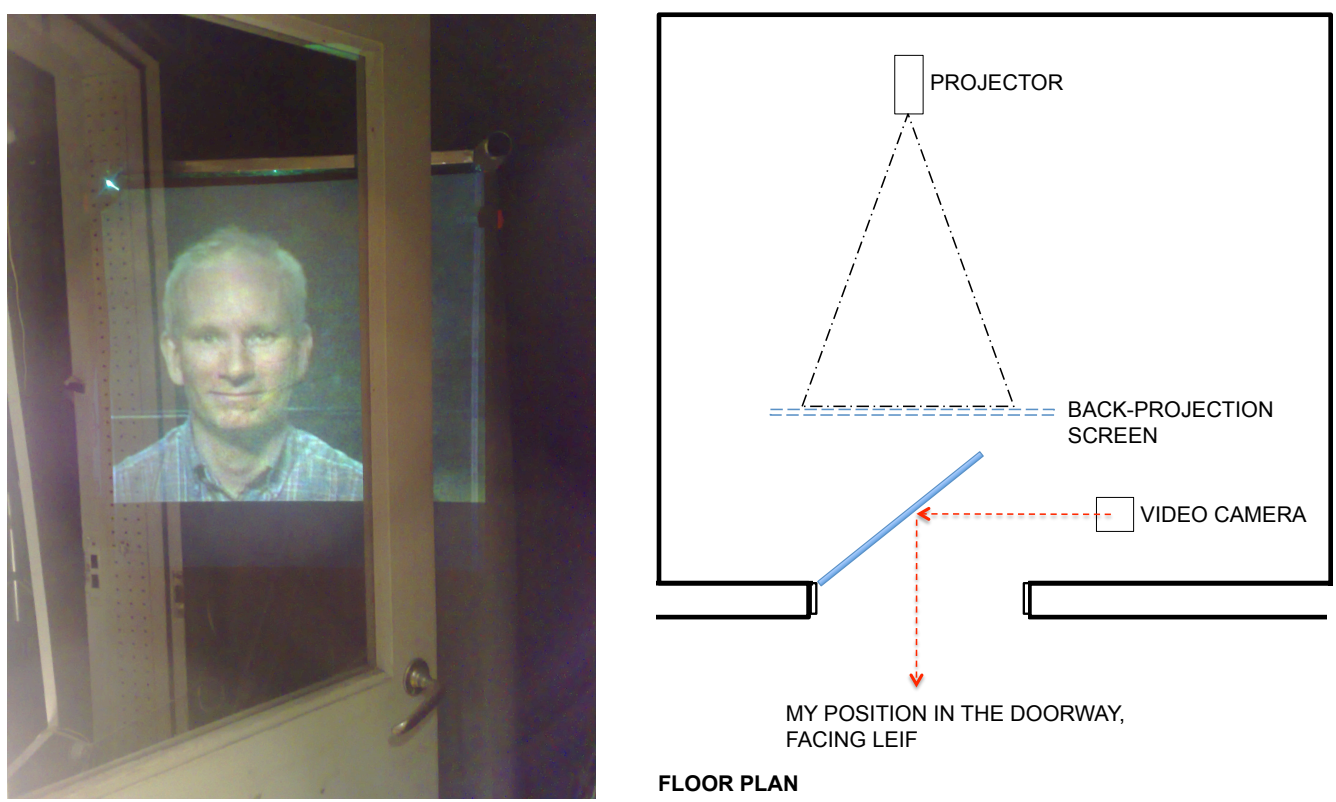

Fig. 14 Our design concept to enable mutual gaze is an adaptation of a patent from 1947 (Rosenthal 1947). The video projector in the background is used for back-projection onto a screen of matted acrylic glass. In this case the back-projection displays my colleague Leif Handberg who looks straight at me, namely at eyelevel. I am standing in the doorway, facing Leif. The glazed door (here, a standard $5 \mathrm{~mm}$ sheet of glass, as part of a 1950s door) opened at $45^{\circ}$ provides sufficient reflection for the video camera. The camera which captures me is hidden to the right, out of view. It is the fact that this camera captures me as I am reflected from the glass at $45^{\circ}$ which enables both parties to experience mutual gaze, without cameras interfering in the projections.

While both examples exposed different design strategies available to presence designers, the example of the mediated therapist specifically illustrated a mediated space where trust must be achieved, and was. With reference to the origins of presence design - a mediated workplace designed at Xerox PARC in the early $1980 \mathrm{~s}^{21}$ - one could characterize the mediated workplace for the therapist as a sustainer - not for a close working relationship, which was the case at Xerox PARC - but for the delicate intimacy and trust which an interaction between therapist and patient represents. The patient, we may conclude, was not here - yet, sufficiently near for the establishment of trust; and for the doctor to perform actions and judgments based on professional skill.

\footnotetext{
${ }^{21}$ A video-mediated work environment for a group of Xerox PARC researchers who were geographically divided between Palo Alto (California) and Portland (Oregon) (Bly et al 1993). The background to this and a few other creative research milieus that formed in the $1960 \mathrm{~s}$, can be found in the development of ubiquitous and tangible computing to support collaboration between people (Weiser 1991).
} 
What we may assert is that since mediated spaces can support such qualified dialogic interaction, as therapy represents, there is reason to further discuss how presence design can be integrated to collaborative work and learning environments where practical knowledge is at core.

Further, the example of the mediated therapist illustrated a focused form of collaboration, where both parties were concentrated on the interaction. However, such face-to-face interaction, to which I will refer as frontal interaction, is only one of many cooperative activities that distinguish teamwork. I will distinguish between frontal versus lateral forms of collaboration that can be supported in workplace design. Heath et al have, in fact, stressed that frontal interaction constitutes a relative small part of working together. It is only "one amongst a diverse configuration of spatial and bodily arrangements through which personnel participate in each other's activities and accomplish the 'business at hand'." (Heath et al 1995: 177). From their observations of earlier media space projects, they conclude that "video technology which primarily provides a face-to-face orientation to users, fails to support peripheral monitoring and peripheral participation, does not provide access to tools, artefacts and the users' local environment, and introduces unanticipated asymmetries into the interaction between users, is unlikely to support even the most basic forms of organisational work." (Ibid.).

In turn, lateral forms of collaboration facilitate peripheral monitoring and awareness in relation to a shared artefact. When office workers sit side by side, they are "continuously sustaining a shared focus on an aspect of a screen or paper-based document, such as a section of an architectural drawing" (Ibid: 176). It is noteworthy that architects were involved as users in the Xerox PARC prototyping process. In effect, sketching together is a crucial part of architectural practice and it is well characterized by Heath et al who summarize that it is not necessarily a case of seeing what another person is seeing, "but rather seeing the other in relation to what he or she is looking at and doing" (Ibid: 178).

While it is noteworthy that many important design criteria were already considered in the first mediated workplaces thirty years ago, such as at Xerox PARC - such as the need for mutual gaze, life size representations, and integration with spatial design (Bly et al 1993) - the concepts of working and meeting were quite different at the time and have, since, acquired significantly different meaning.

\section{The presence-in-person paradigm}

Until very recently, expressions such as 'I'm at work' or 'Let's book a meeting' would by necessity imply the action of going to the office and to sit down at one's desk; or travelling somewhere in order to gather in a conference room to discuss something with someone. In fact, the office as we know it since the $16^{\text {th }}$ century, does exactly this: it provides spatial and technical support for individuals who are gathered in one location in order to produce work, sometimes through collaboration but mostly in solitude.

I put forward that, for a long time, workplace design has been modelled on a presence-in-person paradigm that gives the individual few possibilities to change a pattern of behaviour imposed by 
commuting, travel, and a normative layout of the office. To observe this development I provide a brief account of the history of workplace design which also contextualizes my own experience as an architectural designer. With reference to sources in knowledge management and space syntax theory I will then identify a number of design frictions that may inhibit knowledge-sharing in work and learning environments. In recent years, a paradigm shift in terms of work can be noted, and I briefly address the potential to reform workplace design and discourse, in support of collaborative work practices, where knowledge-sharing is a crucial concern. The Xerox PARC media space is compared to examples from workplace design in the 1990s, which similarly attempted to facilitate knowledgesharing, communication and interaction. Aiming to address the potential effect of presence design on workplace design, I conclude by discussing two possible scenarios.

The development of the office followed the needs to administer the $16^{\text {th }}$ century European feudal society, and for which clerks and scriveners were needed to register taxes and goods. An early example of the prevailing cellular office model, is the Palazzo degli Uffizi, in Florence (ca. 1560), designed by Giorgio Vasari as an annex to the Palazzo Vecchio. Its Swedish equivalent was the central administration of King Gustav Vasa, who allocated a tax office for about thirty office workers, mentioned in a document as early as 1543 (Swedlund 1969: 17).

However, considering recent developments triggered by the process of digital dematerialisation, it is safe to suggest that a paradigm shift has taken place in a very short space of time. ${ }^{22}$ Just fifteen to twenty years ago, the office was, in practical terms, the only place where one could perform one's work tasks. Computers and telephones were attached to sockets in specific locations and neither computer networks nor the Internet were adequately in place to enable an individual to move work from one location to another, even inside the office. (Fig. 15-16) Not only have work patterns changed, but also the philosophy and culture of organisation and workplace (Becker 2004). Mobility of data, in the early 1990s, was still defined by floppy discs - flat precursors to USB memory sticks making it possible to temporarily move documents from a computer in the office to work elsewhere. However, one could always expect that a colleague, who had left, would reappear at the office soon again. Presence in person could be taken for granted; it was the norm.

\footnotetext{
${ }^{22}$ See e.g. Castells et al (2007); Tuner \& Myerson (1999); Donald (2001); Koprowski (2000)
} 


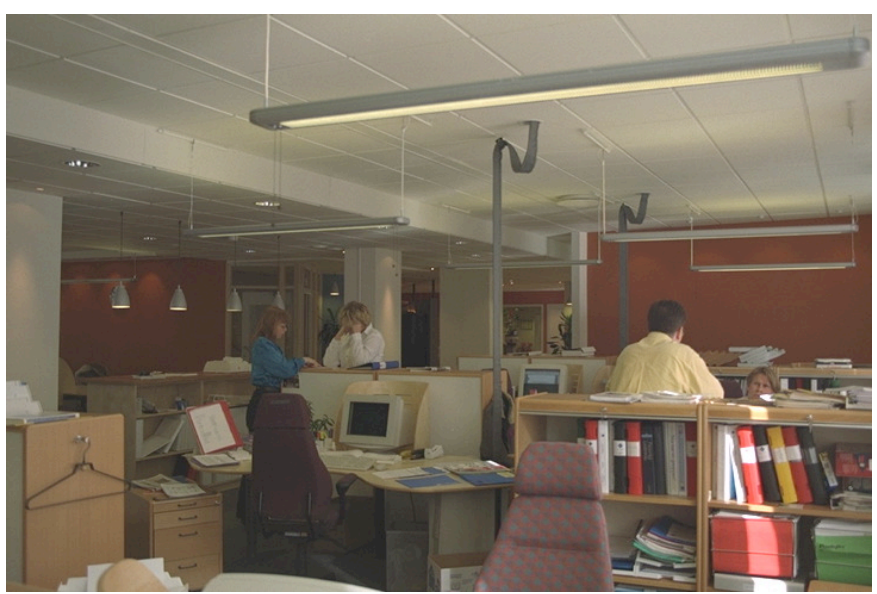

Fig. 15 A typical open plan workplace where presence is taken for granted. Photo taken in Stockholm in the early 1990s.
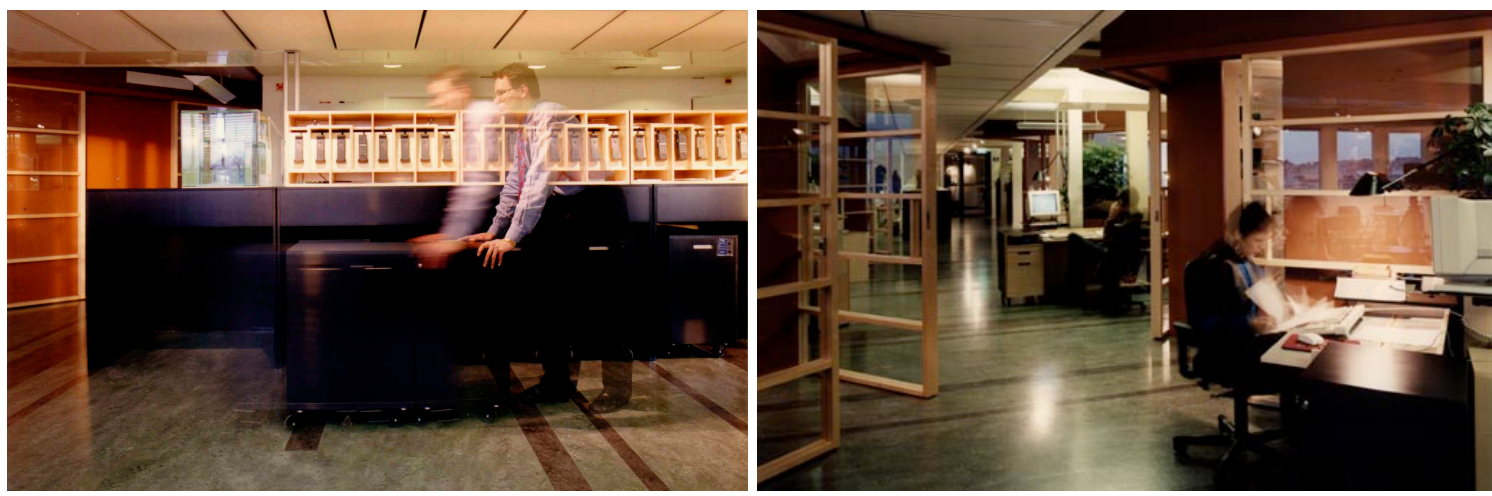

Fig. 16 In the early 1990s, mobility in the workplace was limited and experimental, illustrated by initial attempts to integrate computer networks and cordless telephones to specifically support collaborative practices, as here at Ericsson Business Networks in Stockholm in 1993. Upon entry to the office, an employee would pick up a cordless phone (charging through the night in a dedicated furniture piece), as well as the mail in the pigeon hole and retrieve one' mobile work desk, to sit down by a computer-dock of choice. Computers and plants were integrated to a furniture design distributed around the office. Work was collaborative and organised as short projects lasting 3-10 weeks. Teamwork and documentation were hosted in allocated 'project-pavilions'. Designs by Gullström \& Westerberg Architects.

The concepts of working and meeting have quite recently acquired new meanings in the sense that we no longer take it for granted that a person will undertake a trip or commute to attend a work-related meeting. Most office workers today are engaged in many parallel processes and will decide to travel only after weighing the importance of human interaction against the urgency of their other commitments. People will consider context, time, cost, or environmental reasons, perhaps by thinking, 'Can we possibly do this over the phone? Do I really have to be there? For how long? Are conferencing facilities available?' Without suggesting that human presence has lost its importance in today's work-life, one could perhaps say that we have now entered a phase where presence is negotiated. It is significant to note that in spite of different presence technologies - which enable office workers to participate remotely and to meet, produce and deliver work from mediated spaces away from the office - surprisingly few changes in terms of office design have been seen. Although many different configurations exist, the spatial strategies of the office are still limited, and most can be traced back to the basic and distinct typologies of the cellular and the open plan office (also known as the bull pen). The main difference between these two strategies is that individuals in the former are 
partitioned off from each other by walls in order to ensure distinct audiovisual separation. The spatial strategies are illustrated below. (Fig. 17)
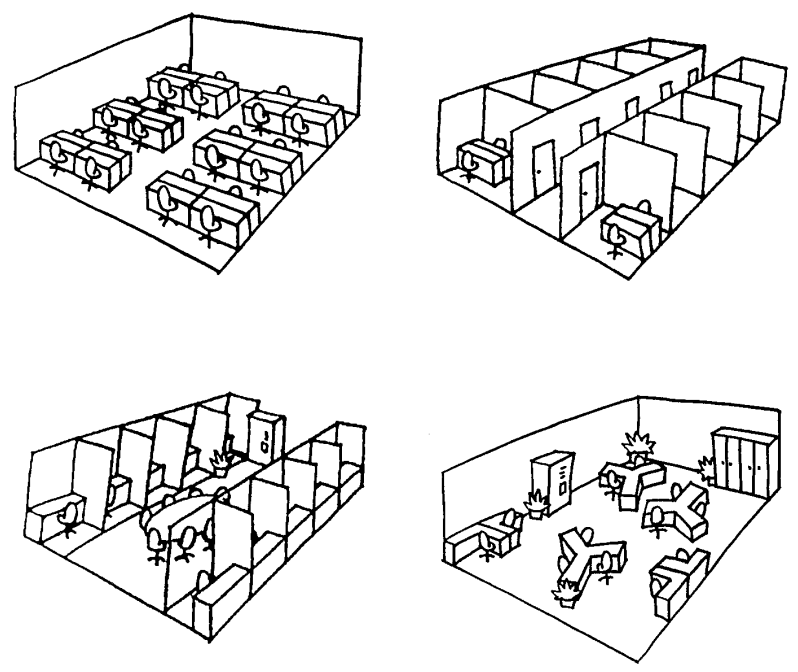

Fig. 17 Varieties of office types in Europe, which all arguably support the presence-in-person paradigm. Clockwise from top left: open plan; cellular, landscape, and combi-office. Human interaction and collaboration is expected to take place in designated 'meeting' areas and 'conference' rooms. (Illustration from van Mehl 2000: 17)

\section{The role of presence for knowledge-sharing and dialogic interaction}

In their analysis of human interaction behaviour in the early mediated spaces of Xerox EuroPARC, Christian Heath, Paul Luff, and Abigail Sellen discussed the limitations of mediated spaces that primarily provided a 'face-to-face, head and shoulders view', stressing that "face-to-face interaction constitutes a relatively small part of working together, and is one amongst a diverse configuration of spatial and bodily arrangements through which personnel participate in each other's activities and accomplish the "business at hand'” (Heath et al. 1995: 177). One conclusion of the Media Space project is that "video technology which primarily provides a face-to-face orientation to users, fails to support peripheral monitoring and peripheral participation, does not provide access to tools, artefacts and the users' local environment, and introduces unanticipated asymmetries into the interaction between users, is unlikely to support even the most basic forms of organisational work" (ibid.).

Based on their prior research on organisational group behaviour, Heath et al. stress that collaborative workplaces in general reveal generic features which are also relevant to mediated environments. In a collaborative setting, co-workers develop "a body of informal and tacit practices for distributing information to each other and coordinating simultaneously multiple activities. These practices allow personnel to distribute information to colleagues and to monitor each other's activities whilst apparently engaged in a single, individual task.” (ibid.: 176)

In effect, what they stress is that face-to-face interaction is only one amongst a variety of cooperative activities which take place in a mediated work environment. They state that "much 
collaboration is undertaken side by side where the individuals are continuously sustaining a shared focus on an aspect of a screen or paper-based document, such as a section of an architectural drawing" (ibid.).

Heath et al. mention the following aspects of collaborative work as significant to mediated interaction:

(1) Focused and unfocused collaboration largely occurs through alignment towards the focal area of activity, such as a document, where individuals coordinate their actions through 'peripheral monitoring';

(2) Collaborative work is dependent on individuals and their subtle and continuous adjustment to each others' activities;

(3) Collaborative work involves ongoing and seamless transitions between individual and collaborative tasks, where staff simultaneously participate in multiple interrelated activities;

(3) An individual's ability to contribute to the activities of others and fulfil their own responsibilities relies upon peripheral awareness and monitoring: "in this way information can be gleaned from the concurrent activities of others within the 'local milieu', and actions and activities can be implicitly coordinated with the emergent task of others";

(4) In co-present working environments, the interaction through which individuals produce, interpret and coordinate actions is accomplished using various objects and artefacts (paper, computers, etc.). Teamwork is rendered visible through these objects and artefacts. (ibid.: 177)

These aspects are useful in that they point to activities in relation to their physical or mediated surroundings. While it is perhaps obvious that such collaborative work primarily takes place outside allocated meeting rooms, i.e. in the actual workplace, it is noteworthy that in terms of the research and development of mediated spaces, there has been an emphasis on face-to-face interaction and supporting formal meetings by means of 'video-conferencing'. Heath et al.'s discussion therefore provides an important point of departure for my own study and serves as the cornerstone of the design work that my colleagues and I have undertaken to support informal and collaborative mediated interaction. Heath et al. conclude:

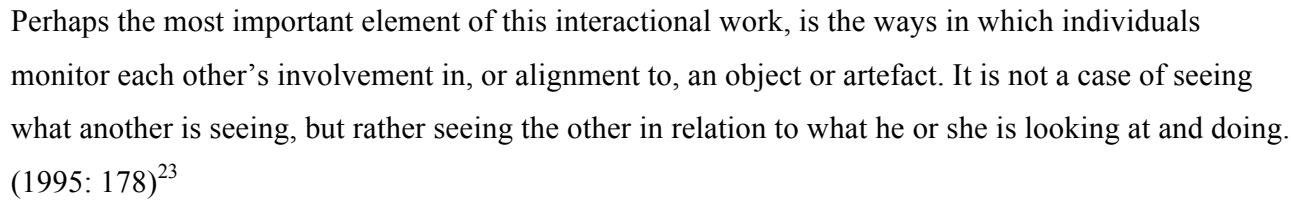

These observations regarding mediated interaction can be related to the concept of dialogism that Mikhail Bakhtin (1984) put forward as a basic principle on which all essential human interaction is

\footnotetext{
${ }^{23}$ At EuroPARC such observations led to a series of user studies conducted by using multi cameras, and a variety of displays, some of which provided a bird's-eye view of the spaces (Heath et al. 1995: 178ff).
} 
based. ${ }^{24}$ For Bakhtin, ideas develop through dialogic relationships with language as a tool. When organisations rely on collaborative work practices, as many do, the underlying assumption is that interpersonal communication and interaction (i.e. human presence) can be linked to knowledgesharing and effective workgroup performance. In consequence, it might also be assumed that a certain spatial layout, e.g. the open plan office, may facilitate such exchange. As many have already shown, these assumptions are grounded in complex epistemological processes that are not directly related to spatial design, but this discussion nevertheless serves to illuminate the presence-in-person paradigm I presented previously. Even if it has proven difficult to establish a causal link between spatial layout and workgroup performance (Sailer 2010; Steen 2010) or knowledge sharing, it may still be an assumption that prevails in workplace design. Practitioners and organizations may use a specific layout, for example 'open plan', in the interest of promoting interaction, collaboration, and knowledge-sharing. It is therefore important to observe which role presence plays in knowledgesharing practices.

My primary aim is to establish whether human presence really is a prerequisite for knowledge sharing in work contexts, or whether mediated presence may also be regarded a viable alternative. If knowledge-sharing is facilitated by mediated presence, the implications for workplace design can be discussed accordingly. To explore these complex issues, I must clarify the concept of organizational knowledge and further address the underlying expectations of presence and interaction in work contexts.

In his seminal book Personal Knowledge, Michael Polanyi presented his notion of a tacit dimension of knowledge $(1958 ; 1962)$. This was followed by Knowing and Being $(1964 ; 1969)$ and The Tacit Dimension $(1966 ; 1983)$. Polanyi addresses the notion that a tacit dimension cannot fully be articulated in words or images: 'knowing' is seen as the outcome of a learning process, often characterized as 'learning by doing'. For Polanyi, all kinds of knowledge contain implicit and explicit dimensions that are interwoven and coexist: "all knowledge is either tacit or rooted in tacit knowledge. A wholly explicit knowledge is unthinkable." (1969: 144) His work has spurred a more recent interest in collaborative work practices where 'human presence' in close and informal interaction enables the sharing of the tacit dimension of knowledge beyond the mere 'transmission of information' (Collins 1974). Polanyi's concept of tacit knowing has been applied to a variety of practices, and researchers from many disciplines have shown that knowledge sharing is fostered through personal communication, interaction and the development of trust over an extended period of time, which is likely to occur, for example, in a master-apprentice relationship. ${ }^{25}$ With time, a form of knowledge that

\footnotetext{
${ }^{24}$ Bakhtin considered the opposite of dialogism to be monologism. He writes: "In the monologic world, tertium non datur: a thought is either affirmed or repudiated: otherwise it simply ceases to be a fully valid thought." (1984: 80)

${ }^{25}$ First applied by scientists within the SSK-tradition (Sociology of Scientific Knowledge), Kuhn's pioneering work, The Structure of Scientific Revolutions (1962), was followed by Collins (1974). Scientific work has since developed in e.g. the areas of knowledge production, management, and innovation (e.g. Nonaka 1994); and in 'evolutionary economics' (e.g.
} 
consists both of habits and skill may evolve within a professional culture, which is shared among the members of a practice. This was reflected in my own study, written in the early 1990s, on the role that tacit knowledge sharing played within architectural discourse, as it was transmitted between generations of architects in early-twentieth-century Stockholm (Gullström 1994) ${ }^{26}$ I have observed the close work and learning relationships that evolved within a group of architects as they combined the roles of leading practitioners and professors. It is important to note that while a master-apprentice relationship facilitates knowledge sharing (notably its tacit dimension), it also conserves and preserves other values embedded in practice, some of which would otherwise have disappeared as other societal developments took place. Thus, professional skill may be acquired and a professional identity strengthened while this conservative role produces a resistance to change. ${ }^{27}$ In the extreme, a professional discourse may be 'out of step' with other developments in society, such as suggested earlier in terms of the current era of digitalisation and its limited impact on work practices. My argument that the presence-in-person paradigm in workplace design is partly maintained by professional discourse may be seen in this light.

To discuss whether presence may be regarded a prerequisite for knowledge sharing in work contexts we must first clarify the concept of organizational knowledge. Davenport and Prusak's definition of knowledge, like many others, stresses that knowledge is essentially related to human action:

Knowledge is a flux mix of framed experience, values, contextual information, and expert insight that provides a framework for evaluating and incorporating new experiences and information. It originates and is applied in the minds of knowers. In organizations, it often becomes embedded not only in documents or repositories but also in organizational routines, processes, and norms. $(1998: 5)^{28}$

This broad definition encompasses a widely accepted distinction between explicit knowledge (information, data) and tacit knowing (experiences, skills, values) in accordance with Polanyi's theory. ${ }^{29}$ It also allows us to relate Wittgenstein's concept of rule-following to the context of organizational knowledge. While Polanyi has shown that knowing is personal, rule-following is not an individual accomplishment, but instead fundamentally based on collectively shared meanings

Nelson \& Winter 1982). As already mentioned, a Swedish focus on professional skill emerged from a social science perspective, with a critical perspective on the effects of computerization in work-life contexts, and which led to the formation of the Skill \& Technology research area (e.g. Göranzon et al. 2006).

${ }^{26}$ As previously mentioned, my thesis for an intermediate doctoral degree (Technical Licentiate), 'The Paradox of Mastery' (Gullström 1994), was written under the guidance of the Skill and Technology programme at the Royal Institute of Technology in Stockholm 1990-94, headed by Göranzon.

${ }^{27}$ My study observed the professionalization process of the architect in Sweden, which, as elsewhere, is characterized by master-apprentice relationships. I identified the conflicting ideals between what remained of a 'Beaux Arts tradition' and what was introduced as a 'polytechnical ideal' in late-nineteenth-century institutions, noting such a resistance to change. ${ }^{28}$ Cf. Nonaka \& Takeuchi 1995: 58ff; as well as the concept of distributed knowledge (Langlois 2003). Drawing on philosopher John Dewey's concept of aesthetic experience (1934), Bell's definition of knowledge stresses the link between action and judgement: "judgement arises from the self-conscious use of the prefix re: the desire to re-order, to re-arrange, to re-design what one knows and thus create new angles of vision or new knowledge for scientific or aesthetic purposes" (Bell 1999: 9).

${ }^{29}$ There is, however, an on-going scientific 'codification debate' regarding to what extent tacit knowing can be made explicit, codified and transferred using certain media; see e.g. Balconi et al. 2007; Cowan et al. 2000; Johnson et al. 2002. 
(Wittgenstein 1953). ${ }^{30}$ While some aspects of organizational knowledge are formal and explicit, these are put into action and given meaning by an organisation's members, such as office workers. Such a Wittgensteinian view is formulated by Barnes (1995: 202), who states that members "must be constituted as a collective able to sustain a shared sense of what rules imply and hence an agreement in their practice when they follow rules." Much of this 'shared sense' is embedded and implicit in workplace design. Architecture and design, in effect, provide a means to represent a certain form of rule-following, which is why an architect will attempt to understand both explicit and formal aspects of organizational knowledge, as well as its underlying and implicit aspects.

\section{Design frictions}

The aim of knowledge sharing (or knowledge transfer, as Davenport and Prusak call it) is to improve an organisation's performance, to increase its value. Knowledge sharing involves the action of transmission (sending or presenting knowledge to a recipient) and absorption by the latter. Unless absorbed and connected to some change in behaviour, knowledge has not been transmitted (Davenport $\&$ Prusak 1998: 101). So far, nothing suggests that human presence is requisite to knowledge sharing, but Davenport and Prusak coined the term 'frictions' to point at a number of cultural factors which may inhibit knowledge sharing (ibid.: 96). Amongst these, lack of trust, lack of common ground (cultural, hierarchical), lack of time, and lack of meeting place are noteworthy aspects in terms of the spatial issues discussed here. Fairly similar results are noted in other disciplines, such as in space syntax theory where it is expressed in more spatial terms that proximity, visibility and layout stimulate interaction. In cognitive science, similar terms are used to discuss factors that contribute to poor synchronizing in human interaction (Argyle \& Cook 1976), such as when the subtleties of nonverbal communication are lost (Heath \& Luff 1991; Rutter et al. 1984). One such feature is eye contact, which is used as a control mechanism in social behaviour, for example, to signal intimacy. Hence mutual gaze is important to the establishment of trust, both in real space as well as in mediated interaction. ${ }^{31}$ While the benefits of information technology in facilitating the transmission of data and explicit knowledge were already quite obvious, we have now identified several aspects which can be related to spatial design, and which matter in terms of tacit knowledge sharing. As noted earlier, the relationship between knowledge sharing, human presence and workplace layout is complex and our aim here has not been to make conclusions, but rather to discuss the expectations of collaborative work practices, and more importantly, whether other means of supporting knowledge sharing in future workplace contexts - for example, remote presence - can be considered as viable solutions. What, in consequence, would be required from workplace design, were organisations to place the same expectations on knowledge sharing in mediated environments? We can use the 'frictions' proposed

\footnotetext{
${ }^{30}$ See e.g. Wittgenstein 1953: $§ 202:$ “And hence also 'obeying a rule' is a practice. And to think one is obeying a rule is not to obey a rule. Hence it is not possible to obey a rule 'privately': otherwise thinking one was obeying a rule would be the same as obeying it."

${ }^{31}$ Op cit: Heath \& Luff 1992; Heath et al. 1995; Rocco 1998; Acker \& Levitt 1987; Ishii \& Kobayashi 1992; Fullwood 2006.
} 
above to discuss whether mediated workplaces support knowledge sharing as adequately as real workplaces. In the following, we will look at recent examples of mediated workplace design to ascertain/discuss whether mediated spaces add to the 'friction' in the development of trust, common ground, time and meeting places. Will remote presence, as enabled by the design prototypes, in effect, reduce the frictions? If so, what is the potential for future workplace design within the emerging paradigm of remote presence?

\section{Conclusions}

It has been argued here that the prevailing spatial strategies in office design favour individual work over collaboration. They are, in fact, remnants of the presence-in-person paradigm. In considering other societal changes, there has been remarkably little development in workplace design in the last century. In spite of many variants, which have seen light through history, there still appears to be an emphasis on supporting individual work, carried out collectively. Individuals often work side by side and share the space, rather than work together. This is a form of collaboration which relies more on division of labour than on dialogic interaction and collaboration, and which hardly can be said to depend on human presence. Weber's concept of 'bureaucracy' and Taylor's of 'scientific management' were represented by an office design of order, hierarchy, supervision and efficiency in the early 1900 s, but in many ways still prevails. ${ }^{32}$ At the time, the task of office workers was to keep records and manage information, carry out meetings and discussions, make calculations, produce text, make decisions and plans. This mechanistic view of the workplace was visible in the physical planning of the workplace and implemented Taylor's idea of 'economy of motion, 'visual accessibility' and 'supervision' ${ }^{33}$ Although contemporary work life may appear radically transformed by collaborative ways of working, we discover that, under the surface, much stays the same.

How important is presence? Is it slowly losing importance in work life contexts? Or is workplace design irrelevant to the development of organizational knowledge? These are complex and related issues which this essay has attempted to address, but which require further discussion.

Attempting to conclude the discussions so far, two scenarios can finally be drafted. In the first, copresence between workers is considered crucial for knowledge exchange and the production of organizational knowledge. Such a co-presence scenario will, I argue, require support from innovative

\footnotetext{
32 Weber (1947) and Taylor (1911) are the two main contributors to classical organization theory. Taylor's organisational theory for 'scientific management' was presented in 1911 and focused on work performance and efficiency. For Taylor, work needed to be broken down into its smallest elements and using the methods of 'motion study', its most efficient procedures were to be identified. Weber's theory is not directly related to spatial organisation. However, as noted by Sundstrom, an employee's rank in the organisational hierarchy is represented through the use of signifiers in the workplace design, such as location, size of their workspace or furniture design. Sundstrom (1986) describes the relationship between the worker and workplace as a 'cog to a machine' and Donald, similarly, as follows: "Employees were viewed as extrinsically motivated and so intrinsically lazy, working only under supervision and motivated by financial gain alone. It was believed that when given the appropriate conditions, people would work to their optimum efficiency." (Donald 2001: 285).

${ }^{33}$ Sundstrom (1986:49) describes that around 1900 there was an interest among psychologists on the effect from the work environment on human behaviour. The influence of noise, temperature, ventilation and lighting was measured and related to the performance of workers. Such monitoring often produced negative result and workers' stress levels increased as a result from hiding their emotions. (Cf. Donald 2001).
} 
workplace design, informed by presence design to enable mediated interaction and based on the concept of witnessed mediated presence.

A second, more dystopian office scenario, which however also is likely, is considered by assuming that organisations rely more on individual contribution than on forms of collaboration which require interaction. In such a scenario - which I label no-presence scenario - information exchange between workers is supported by different media and communication tools, but it is of less importance to gather staff in the workplace. In consequence, the office loses its capacity as a site for collaboration and knowledge exchange. Rather, the office risks to become a site for storage while the parallel development of mobile technical devices enable workers to contribute their individual share from remote locations - collaboration in its most basic form, supported by mere information exchange.

Without a genuine need for knowledge-sharing or human interaction as part of the collaboration, the benefits in sharing spaces with others at work remain vague and related to either economical (less space per worker) or social measures (particularly in case of routine work). Given the choice, it is likely that many workers will choose an individual office cell before an open plan workspace arguing the need for seclusion rather than presence - or opt for the possibility, at least sometimes, to just work remotely from home..$^{34}$ There is a great risk that the office, as we know it, has become redundant, hence my challenge to fellow architects to engage in presence design.

Presence design is architecture.

\section{Acknowledgements}

As this paper builds on research undertaken while I was Director of the VINNOVA Centre of Excellence for Sustainable Communications at KTH Royal Institute of Technology, Stockholm, I want to thank the Swedish Governmental Agency for Innovation Systems for funding our interdisciplinary group of researchers since 2006, based on a vision that video-mediated communications can promote innovative thinking in terms of a sustainable development. My current research platform in Presence Design is a productive outcome of this ambitious venture, to which I have been able to commit myself fully over the last two years, by exploring the contribution from architecture to the broader field of ICT-mediated human activity. I specifically wish to thank Ove Anebygd at Ericsson AB for giving me full access to the Ericsson 'Teleworker and Video Presence' study; Aase Schibsted Knudsen for allowing me to use Atwood in Norway as a fruitful example of presence design; and Agneta Ekman, $\mathrm{MD}$, private consultant and specialist in psychiatry and occupational health, for her participation in a

\footnotetext{
${ }^{34}$ Discussing future trends, Koprowski (2000) argues that workplace flexibility is more important than job stability, salary, holiday time and benefits. Flexibility is often perceived as a status symbol. Similarly, Challenger writes: "Driven by employee demand for more-flexible scheduling, telecommuting will be the predominant workplace trend in the new millennium" (Challenger 2000:38). The above is supported by a user study aiming to define the drivers and barriers for teleworking in Sweden and Italy conducted by Ericsson AB. It asserts that in Sweden, an office worker expects a certain amount of teleworking, as part of the job, partly because the job requires an involvement beyond what can be achieved within a fixed number of working hours, partly because employees enjoy the freedom of structuring their own work time. In contrast, Italian white collar workers do not assume teleworking is offered in the job. It is regarded "an exclusive option, primarily for those who are in more senior positions and have shown their employer that they can be trusted." (Ericsson AB 2008)
} 
user study in which she treated twenty patients remotely. My close colleague Leif Handberg, Senior Lecturer in Media Technology, KTH, deserves utmost recognition for his insights during our collaboration and friendship, which has now spanned more than ten years.

\section{References}

Acker S, Levitt S (1987) Designing Videoconference Facilities for Improved Eye Contact. Journal of Broadcasting \& Electronic Media 31(2): 181-191

Alberti L B (Ca 1435-1436, 1970) On Painting, trans. by Spencer J R. New Haven, Yale University Press [Original Latin edition (1540) De pictura praestantissima: Basel, Italian trans. (1547) Della pittura: Venice. downloaded $100809<$ http: //www.noteaccess.com/Texts/Alberti/>]

Allen, T J (1977) Managing the Flow of Technology. Cambridge, MIT Press

Argyle M, Cook M (1976) Gaze and Mutual Gaze. Cambridge, Cambridge University Press

Bakhtin M (1984) Problems of Dostoevsky's Poetics, ed. and trans. by Emerson C. Minneapolis, University of Minnesota Press

Balconi M, Pozzali A, Viale R (2007) The "Codification Debate" Revisited: A Conceptual Framework to Analyze the Role of Tacit Knowledge in Economics', Industrial and Corporate Change, Vol. 16(5): 823-849

Barnes B (1995) The Elements of Social Theory. London, UCL Press

Becker F (2004) Offices at Work: Uncommon Workspace Strategies that Add Value and Improve Performance. Hoboken, John Wiley \& Sons

Bell D (1999) The Axial Age of Technology. In: Bell D. The Coming of the Post-Industrial Society. New York, Basic Books

Bly S, Harrison S, Irwin S (1993) Media Spaces: Bringing People Together in a Video, Audio and Computing Environment. Communications of the ACM, 36: 28-46.

Buxton W (1992) Telepresence: Integrating Shared Task and Person Spaces. Proceedings of Graphics Interface '92, pp. 123129

Castells M, Fernández-Ardèvol M, Linchuan Qiu J, Sey A (2007) Mobile Communication and Society. Cambridge, MIT Press

Challenger J A (2000) Trends Reshaping the Workplace. The Futurist, Sept-Oct: 35-41

Collins H M (1974) TEA SET - Tacit Knowledge and Scientific Networks. Science Studies 4(2): 165-185

Cowan R, David P A, Foray, D (2000) The Explicit Economics of Knowledge Codification and Tacitness. Industrial and Corporate Change. Oxford University Press. Vol. 9(2): 211-53

Dagbladet (2008) 30 May. Se den virtuelle midnatssromansen $<$ www.dagbladet.no/tv/index.html?clipid=26826> Accessed 9 June 2009

Danbolt G (1979) Bilde og praksis. In: Danbolt G, Johannessen K S, Nordenstam T. Den Estetiske Praksis. Bergen, Universitetsförlaget, pp. 64-118

Davenport T, Prusak L (1998) Working Knowledge: How Organizations Manage what they Know. Cambridge, Harvard Business Press

De las Cuevas C, Arredondo M T, Cabrera M F et al (2006) Randomized Clinical Trial of Telepsychiatry through Videoconference versus Face-to-Face Conventional Psychiatric Treatment. Telemedicine and e-Health, 12(3): 341-350

Dewey J $(1934,1980)$ Art as Experience. New York, Perigee Books

Dick P, Filler R, Pavan A (1999) Participant Satisfaction and Comfort with Multidisciplinary Pediatric Tele-medicine Consults. Journal of Pediatric Surgery, 34: 137-142

Donald I (2001) Emotion and Offices at Work. In: Payne, R. L. and Cooper, C. L. (eds.) Emotions at Work: Theory, Research and Applications for Management. New York, John Wiley \& Sons

Eisenstein, S 1992. Towards a Theory of Montage, ed. by Taylor, R, and Glenny, M., trans. by Glenny, M. (London: British Film Institute)

Eisenstein, S. Ca. 1938, 1989. 'Montage and Architecture', reprinted in Assemblage, 10: 111-131

Ekman A (2009) Eye2Eye Telepsychiatry. Poster presented at the American Psychiatry Association 2009 Annual Meeting. San Francisco, May 16-21, 2009

Ericsson AB (2008) Exploring the Potential of Teleworking and Video Presence, Results from Sweden and Italy. User study conducted by Ericsson AB in collaboration with Augur Marknadsanalys. Stockholm, Sweden

Foucault M $(1966,1989)$ The Order of Things. Guildford, Routledge

Fullwood C (2006) The Effect of Mediation on Impression Formation: A Comparison of Face-to-Face and Video-Mediated Conditions. Applied Ergonomics, 38: 267-273

Gullström C (1994) Mästerskapets Paradox: Om yrkeskunnande och kunskapsöverföring i den svenska arkitekturen under 1900-talet. Licentiate dissertation, KTH Royal Institute of Technology

Gullström, C (2010) Presence Design: Mediated Spaces Extending Architecture. Doctoral dissertation, KTH Royal Institute of Technology (http://kth.diva-portal.org/smash/record.jsf?searchId=1\&pid=diva2:349960) 
Gunter T D (2009) Forensic Telepsychiatry. In: Elissa P et al. Principles and Practice of Child and Adolescent Forensic Mental Health. Arlington, American Psychiatric Publishing

Gunter, T.D. 2009. 'Forensic Telepsychiatry', in Elissa, P. et al. Principles and Practice of Child and Adolescent Forensic Mental Health (Arlington: American Psychiatric Publishing)

Göranzon B, Hammarén M, Ennals R (eds.) (2006) Dialogue, Skill and Tacit Knowledge. London, John Wiley \& Son

Heath C, Luff P (1991) Disembodied Conduct: Communication through Video in a Multimedia Environment. Proceedings of CHI '91 Human Factors in Computing Systems (ACM: New York), pp. 99-103

Heath C, Luff P (1992) Media Space and Communicative Asymmetries: Preliminary Observations of Video-Mediated Interaction. Human-Computer Interaction, 7(3): 315-346

Heath C, Luff P, Sellen A (1995) From Video-mediated Communication to Technologies for Collaboration: Reconfiguring Media Space. In: Emmott, S. J. Superhighways: Multimedia Users and Futures. Cambridge, Cambridge University Press

Held R M, Durlach N I (1992) Telepresence. Presence 1: 109-112

Hillier B (1996) Space is the Machine: A Configurational Theory of Architecture. Cambridge, Cambridge University Press

IJsellsteijn W, Riva G (2003) Being There: The Experience of Presence in Mediated Environments. In: Riva G, Davide F, IJsselsteijn W (eds.) Being There: Concepts, Effects and Measurement of User Presence in Synthetic Environments. Amsterdam, IOS Press

IJsselsteijn W A (2004) Presence in Depth. Doctoral dissertation, Eindhoven University of Technology

Ishii H, Kobayashi M (1992) Clearboard: A Seamless Medium for Shared Drawing and Conversation with Eye Contact. Proceedings of SIGCHI Conference on Human Factors in Computing Systems, pp. 525-532

Janik A (1994) The Bergen School of Aesthetics. In: Johannessen K S, Larsen R., Åmås K O. Wittgenstein in Norway. Oslo, Solum, pp. 197-216

Johnson B, Lorenz E, Lundvall B A (2002) Why All this Fuss about Codified and Tacit Knowledge? Industrial and Corporate Change, Vol. 11(2): 245-262

Keating E, Mirus, G (2003) American Sign Language in Virtual Space: Interactions between Deaf Users of ComputerMediated Video Communication and the Impact of Technology on Language Practices. Language in Society, Vol. 32 , No. 5: 693-714

Knudsen, C., and Puijik, R. 2009. 'Presence Production in Live Television: Experiments in Interaction and Mediation in a Digital Environment', Proceedings of the Seventh European Conference on European Interactive Television, Loween, Belgium (New York: ACM)

Koprowski G J (2000) The New Workplace Flexibility: Flexibility in the Workplace is an Increasing Concern', $<$ Informationweek.com>: 212-218.

Kuhn T S (1962) The Structure of Scientific Revolutions. Chicago, Chicago University Press

Ladwein M (2006) Leonardo da Vinci: The Last Supper. A Cosmic Drama and an Act of Redemption. Germany, Temple Lodge Publishing

Langlois R N (2003) The Vanishing Hand: The Changing Dynamics of Industrial Capitalism', Industrial and Corporate Change, 12(2): 351-385

Latifi R (2008) Current Principles and Practices of Telemedicine and E-Health. Amsterdam, IOS Press

Lombard M, Ditton T (1997) At the Heart of it all: The Concept of Presence. Journal of Computer-Mediated Communication. University of Southern California, Vol. 3, No. 2

Morazin, J. 1997. ‘A New Regional Dynamic', Forces, 115: 46-49

Nelson R R, Winter, S G (1982) An Evolutionary Theory of Economic Change. Cambridge, Harvard University Press

Nevejan C (2007) Presence and the Design of Trust. Doctoral dissertation, University of Amsterdam

Nevejan C (2009) Witnessed Presence and the YUTPA Framework. PsychNology, Vol. 7, 1: 59-76

Nonaka I (1994) A Dynamic Theory of Organizational Knowledge Creation. Organization Science, 5(1): 14-37

Nonaka I, Konno N (1998) The Concept of "Ba": Building a Foundation for Knowledge Creation. California Management Review, Vol. 40, No. 3: 40-54

Nonaka I, Takeuchi H (1995) The Knowledge-creating Company: How Japanese Companies Create the Dynamics of Innovation. New York: Oxford University Press

Norman S (2006) The Use of Telemedicine in Psychiatry. Journal of Psychiatric and Mental Health Nursing, 13: 771-777

O’Reilly R, Bishop J, Maddox K et al (2007) Is Telepsychiatry Equivalent to Face-to-Face Psychiatry? Results from a Randomized Controlled Equivalence Trial. Psychiatry Serv, 58: 836-843

Polanyi M $(1958,1962)$ Personal Knowledge. Chicago, Chicago University Press

Polanyi M $(1966,1983)$ The Tacit Dimension. Gloucester: Doubleday \& Co

Polanyi M (1969) The Logic of Tacit Inference. In: Grene, M (ed.) Polanyi, Knowing and Being: Essays by Michael Polanyi. Chicago, Chicago University Press

Rocco E (1998) Trust Breaks Down in Electronic Contexts but can be Repaired by some Initial Face to Face Contacts. Proceedings of CHI, 1998: 496-502

Rosenthal A H (1947) Two-way Television Communication Unit. United States Patent 2,420,198, May 6, 1947, available at $<$ http://www.freepatentsonline.com/2420198.html> 
Rutter D R, Pennington D C, Dewey M E, Swain J (1984) Eye-contact as a Chance Product of Individual Looking: Implications for the Intimacy Model of Argyle and Dean. Journal of Nonverbal Behaviour, pp. 250-358

Sailer K (2010) The Space-Organisation Relationship: On the Shape of the Relationship between Spatial Configuration and Collective Organisational Behaviours. Doctoral dissertation, Technical University of Dresden

Schön D A (1983) The Reflective Practitioner. Michigan, Basic Books

Senju A, Hasegawa T (2005) Direct Gaze Captures Visuospatial Attention. Visual Cognition, No. 12

Simon H A (1969) The Sciences of the Artificial. Cambridge, MIT Press

Sinha A (2000) An Overview of Telemedicine: The Virtual Gaze of Health Care in the Next Century. Medical Anthropology Quarterly: New Series, Vol. 14, No. 3 (Sep. 2000): 291-309

Steen J (2009) Spatial and Social Configurations of Space. In: Koch D., Marcus L, Steen J (eds.) Proceedings of the $7^{\text {th }}$ International Space Syntax Symposium. Stockholm, KTH Royal Institute of Technology

Steinberg L (1973) Leonardo's Last Supper. The Art Quarterly, 36(4): 297-410

Steinberg L (1995) The Seven Functions of the Hands of Christ: Aspects of Leonardo's Last Supper. In: ApostolosCappadona, D. (ed.) Art, Creativity, and the Sacred: An Anthology in Religion and Art. New York, Continuum

Steinberg L (2001) Leonardo's Incessant Last Supper. Canada, Zone Books

Summers D (2003) Real Spaces. New York, Phaidon

Sundstrom E (1986) Work Places: The Psychology of the Physical Environment in Offices and Factories. NewYork, Cambridge University Press

Swedlund R et al (1969) Byggnadsstyrelsen och dess föregångare, Att förse riket med beständige och prydlige byggnader. Stockholm, Byggnadsstyrelsen

Taylor F W (1911) The Principles of Scientific Management. New York and London, Harper \& Brothers

Tuner G, Myerson J (1999) New Workspace, New Culture: Office Design as a Catalyst for Change. London, Gower

van Meel J (2000) The European Office: Office Design and National Context. Doctoral dissertation, TU Delft

Weber M (1947) The Theory of Social and Economic Organization. New York: Oxford University Press

Weiser, M. 1991. 'The Computer for the Twenty-First Century', Scientific American, September 1991: $94-10$

Wittgenstein L $(1953,1991)$ Philosophical Investigations, ed. by Anscombe G E M, Rhees R, von Wright G H, trans. by Anscombe G E M. Oxford, Basil Blackwell 